\title{
WestVirginiaUniversity
}

THE RESEARCH REPOSITORY @ WVU

Graduate Theses, Dissertations, and Problem Reports

2013

\section{On the Origin of Shame: Feelings of Disgust toward the Self}

John A. Terrizzi Jr.

West Virginia University

Follow this and additional works at: https://researchrepository.wvu.edu/etd

\section{Recommended Citation}

Terrizzi, John A. Jr., "On the Origin of Shame: Feelings of Disgust toward the Self" (2013). Graduate Theses, Dissertations, and Problem Reports. 134.

https://researchrepository.wvu.edu/etd/134

This Dissertation is protected by copyright and/or related rights. It has been brought to you by the The Research Repository @ WVU with permission from the rights-holder(s). You are free to use this Dissertation in any way that is permitted by the copyright and related rights legislation that applies to your use. For other uses you must obtain permission from the rights-holder(s) directly, unless additional rights are indicated by a Creative Commons license in the record and/ or on the work itself. This Dissertation has been accepted for inclusion in WVU Graduate Theses, Dissertations, and Problem Reports collection by an authorized administrator of The Research Repository @ WVU.

For more information, please contact researchrepository@mail.wvu.edu. 
On the Origin of Shame: Feelings of Disgust toward the Self

John A. Terrizzi Jr.

Dissertation submitted to the Eberly College of Arts and Sciences at West Virginia University in partial fulfillment of the requirements for the degree of

Doctor of Philosophy in Psychology

Natalie J. Shook, Ph.D., Chair

Amy Fiske, Ph.D.

Amy Gentzler, Ph.D.

Kevin Larkin, Ph.D.

Joshua Woods, Ph.D.

Department of Psychology

Morgantown, West Virginia

2013

Keywords: Disgust, Shame, Emotion 


\section{Abstract \\ On the Origin of Shame: Feelings of Disgust toward the Self}

\section{John A. Terrizzi Jr.}

Shame and disgust are believed to be evolved psychological solutions to different adaptive challenges and, thus, independent emotions. Shame is thought to promote the maintenance of social hierarchies (Gilbert, 1997; Fessler, 2004), whereas disgust is believed to encourage disease avoidance (Curtis et al., 2004; Oaten et al., 2009). Although shame and disgust are often treated as orthogonal emotions, they share some important commonalities. Both shame and disgust involve bodily concerns, have been described as moral emotions, and encourage avoidance of social interaction. The purpose of the current studies was to investigate the relation between shame and disgust. More specifically, the current research examined whether shame is experienced, at least in part, as disgust toward the self. As shame is often confounded with guilt (Tangney et al., 2007), it was important to demonstrate the uniqueness of the relation between shame and disgust. Thus, guilt was included as a comparison variable. In Study 1, disgust sensitivity and fear of contamination were positively correlated with shame, but not guilt, even after controlling for guilt and negative affect. In Study 2, a disgust induction increased shame, but not guilt, for individuals who were sensitive to disgust. In Study 3, a disgust induction led to an unanticipated significant reduction in shame, whereas a purity induction did not affect shame. In Study 4, inducing disgust increased shame for those who were less sensitive to disgust, but not for those who were more sensitive to disgust. The current research provides initial evidence that there is a unique relation between shame and disgust. Across all 4 Studies, disgust sensitivity and shame propensity were positively correlated even after controlling for negative affect and guilt propensity. However, the results of the three experimental studies provide conflicting evidence as to the causal nature of this relation. 


\section{Acknowledgements}

I would like to thank my 3-year-old daughter, Aria Rose, for being the little voice of reason throughout the dissertation process. I would also like to thank my loving wife, Dawn, for her continual encouragement. Additionally, this work would not have been possible without the invaluable contribution of my Advisor, Natalie Shook. She has provided me with exceptional guidance throughout my graduate career and her endless constructive feedback has made me a better researcher. I would also like to thank my dissertation committee: Amy Fiske, Amy Gentzler, Kevin Larkin, and Joshua Woods for providing valuable insights that have improved the quality of my work. Lastly, I would like to thank all of the undergraduate research assistants who were instrumental in the data collection process. 


\section{Table of Contents}

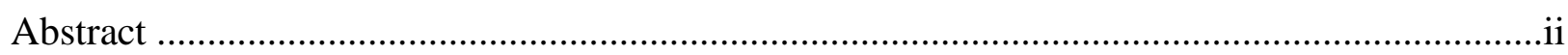

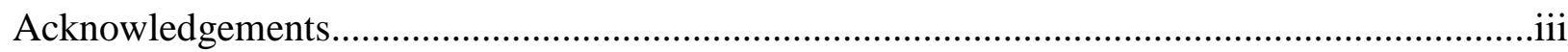

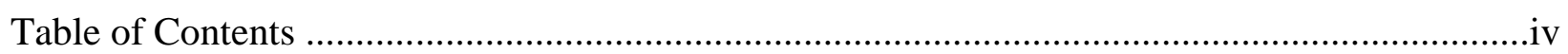

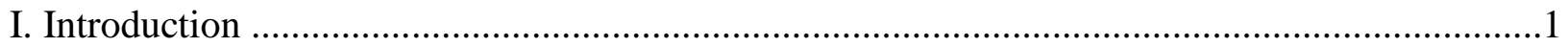

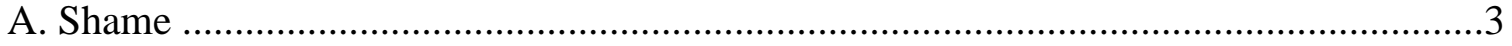

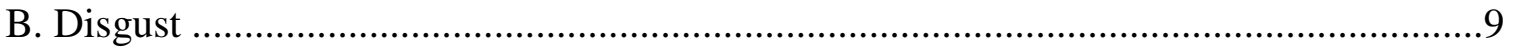

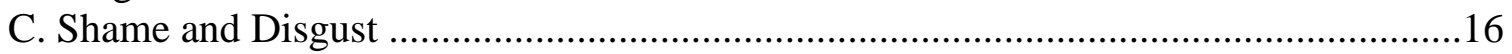

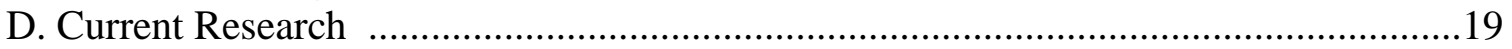

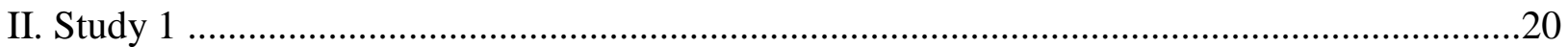

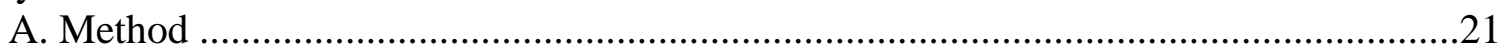

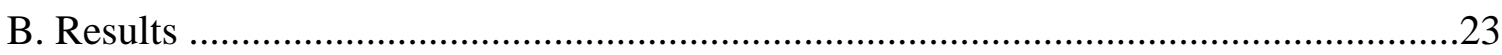

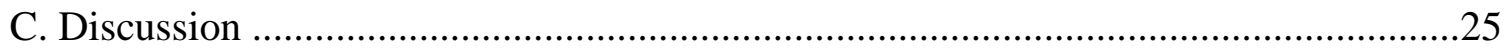

III. Study 2

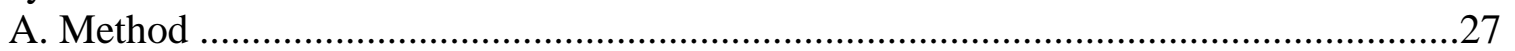

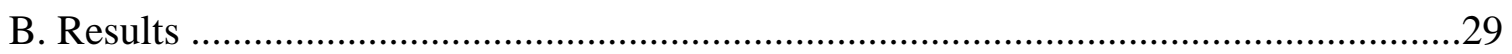

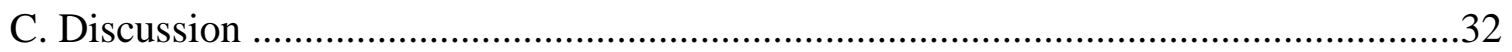

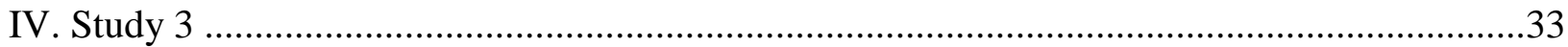

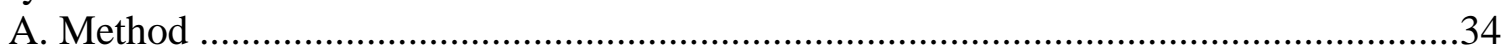

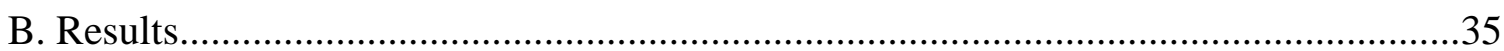

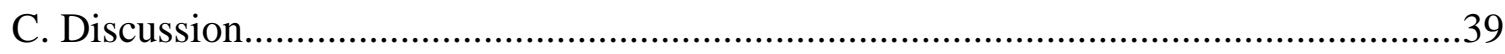

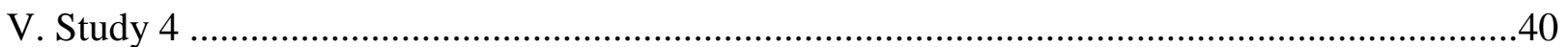

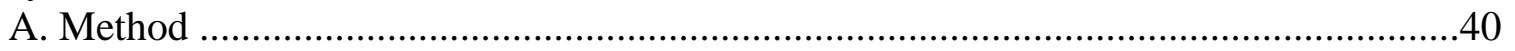

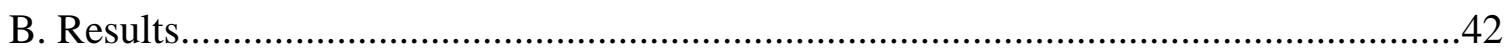

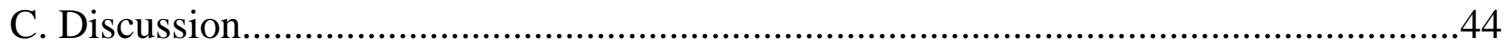

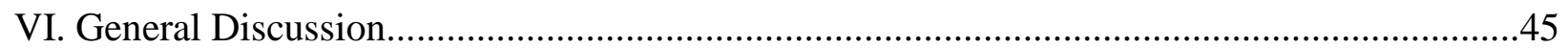

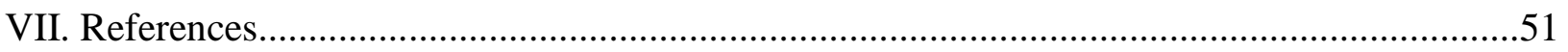

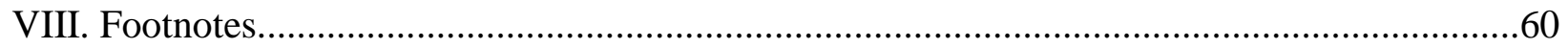

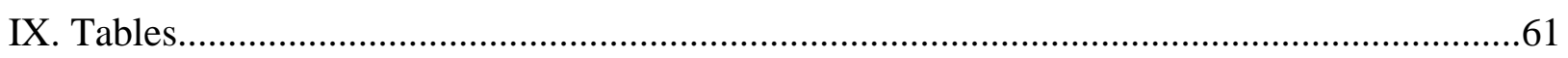

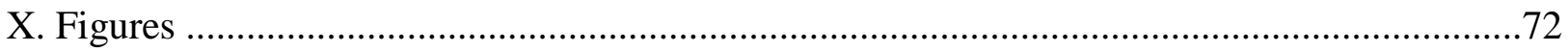

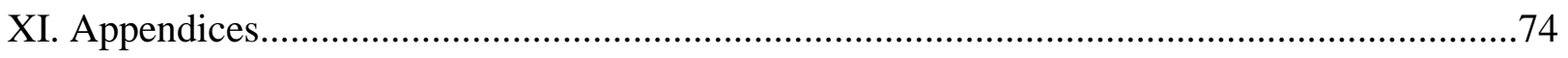

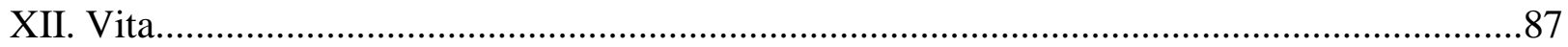


On the Origin of Shame: Feelings of Disgust toward the Self

Traditionally, shame and disgust have been treated as orthogonal emotions. Whereas disgust has been described as a basic or primary cross-cultural emotion (Ekman et al., 1987), shame has been discussed as a secondary self-conscious emotion (Tangney et al., 2007). However, shame and disgust share several important similarities. Both shame and disgust involve bodily concern, have been described as moral emotions, and encourage avoidance of social interaction. The current work took a novel approach to understanding the emergence of the self-conscious emotion of shame. More specifically, the current work operated under a theoretical framework in which self-conscious emotions (e.g., shame) emerge when primary emotions (e.g., disgust) are reflected on the self. In other words, shame may be experienced as disgust with the self.

Indeed, the parallels between shame and disgust can be found in classic literary symbolism. In Samuel Taylor Coelridge's (1798/1992) epic poem, The Rime of the Ancient Mariner, the protagonist, the mariner, commits a moral transgression in which he shoots an albatross. The albatross was considered by seamen to be a symbol of good fortune and its murder was believed to unleash a curse. As a result of his crime, the mariner was shamed by having to wear the dead albatross around his neck as a symbol of his moral indiscretion. Shame is similarly symbolized in Nathanial Hawthorne's (1850/1956) The Scarlet Letter in which the main character is required to wear a scarlet " $\mathrm{A}$ " as penance for committing adultery. Both of these literary examples of shame illustrate the bodily nature of shame in that the moral transgressions were linked to the self (i.e., wearing the carcass of the albatross and the scarlet “A”). They also illustrate the utility of shame to discourage individuals from engaging in undesirable behaviors (i.e., shooting an albatross and adultery). 
Relatedly, the emotion of disgust has been linked to the emotional consequences of moral transgressions. Within many religious traditions (e.g., Christianity), moral violations are characterized as a stain or defilement as if the body has been contaminated (Ricoeur, 1967). In order to cleanse the body from sin, many religions incorporate physical (e.g., baptism) and symbolic (e.g., confession) purity rituals that are meant to cleanse the "soul" of moral contamination. References to moral purity appear throughout the Bible. For example, one passage reads, "Wash me thoroughly from mine iniquity, and cleanse me from my sin" (Psalms 51:2). Moreover, one of the New Testament's most infamous characters, Pilate, in an attempt to evade any moral responsibility for the execution of Jesus "took some water and washed his hands before the crowd, saying 'I am innocent of this man's blood"” (Matthew 27:24). Similar symbols of moral cleanliness can be seen in other classic works. In Shakespeare's (1623/1926) Macbeth, Lady Macbeth furiously washes her hands to remove the moral stain of plotting a murder. Together, these literary examples illustrate how the commission of moral transgressions can lead to disgust with the self.

From an evolutionary perspective, human emotions have been treated as independent mechanisms that have evolved to solve different adaptive challenges (Darwin, 1872; Nesse \& Ellsworth, 2009). Shame is thought to have evolved to facilitate social order and hierarchy (Fessler, 2004; Gilbert, 1997), whereas disgust is believed to be an evolved disease-avoidance mechanism (Oaten, Stevenson, \& Case, 2009). However, emotions are not always easily disentangled from one another. As the literary examples above suggest, the historical symbolism of shame seems to overlap with contamination concerns. Moral transgressors are marked by their immoral acts. They are stigmatized either by society (i.e., shaming tactics) or by the commission of the moral violations themselves (i.e., the stain of sin), as if they were a source of 
contamination with which others should not interact or risk contamination. The current research examined the relation between shame and disgust to determine whether the association between the two emotions is the result of overlapping evolved psychological mechanisms. Rather than a merely symbolic relationship, the relation between shame and disgust may provide an example of how self-conscious emotions can emerge when primary emotions are reflected on the self. Specifically, shame was proposed to be the emotional consequence of perceiving the self as a source of contamination. That is, shame may be, at least in part, disgust with the self.

\section{Shame}

Shame is considered broadly as a self-conscious emotion, or an emotion that involves self-reflection and evaluation (Tangney, 2003). That is, the experience of shame encourages self-evaluative ruminations that are degrading and pervade all aspects of the self (i.e., both physical and psychological). As such, the self is perceived as innately flawed. Thus, shame is a negatively valenced self-conscious emotion that results in global self-condemnation (Niedenthal, Tangney, \& Gavanski, 1994; Tangney, 1991).

Shame can be triggered by both moral transgressions (e.g., cheating) and social norm violations (e.g., failing to meet others' expectations; Ferguson, Steggie, \& Damhuis, 1991; Keltner \& Buswell, 1996). For example, Ferguson and colleagues (1991) demonstrated that imagining scenarios in which one was either responsible for damaging somebody's property (i.e., moral transgression) or passed gas in public (i.e., norm violation) both elicited shame. Public exposure (i.e., the presence of others) also increases the likelihood of experiencing shame (Smith, Webster, Parrott, \& Eyre, 2002). That is, if others witness the social norm violation, there is a greater likelihood that the transgressor will experience shame. As such, shame appears 
to serve an important social function as an internal regulatory system, which discourages moral or social norm violations.

It is important to note that although shame shares many similarities with its sibling moral emotion, guilt, they are considered distinct emotions. Both shame and guilt are negative emotions that involve self-conscious evaluation and lead to the inhibition of immoral behavior (Haidt, 2003; Tangney, Stuewig, \& Mashek, 2007). Shame and guilt are also very highly correlated (i.e., people who are prone to shame are also prone to guilt and vice versa) and are often used interchangeably among laypersons. However, empirical evidence suggests that they are, indeed, different emotional experiences that lead to very different psychological and behavioral outcomes (Tangney, 1991). One important characteristic that distinguishes shame from guilt is the object that is the focus of self-conscious scrutiny (Lewis, 1971). In the case of shame, the self or one's physical body is the attitude object, whereas with guilt, the attitude object is an action or behavior. In response to a moral transgression, a person who is experiencing shame would be likely to think "I am a bad person" whereas someone who is experiencing guilt would be likely to think "I did a bad thing" (Niedenthal et al., 1994). In other words, shame can be described as intense negative feelings directed toward the self (Ausubel, $1955)$.

Compared to guilt, shame is considered to be the "ugly" moral emotion because unlike guilt, shame is characterized by global self-condemnation and self-oriented personal distress (Niedenthal, et al., 1994; Tangney, 1991). As a result, shame is considered to be the most painful of the self-conscious emotions. In fact, some theorists have argued that the pain associated with shame can be so intense that those who suffer from chronic shame may perceive suicide as the only means of escape (Hastings, Northam, \& Tangney, 2000; Mokros, 1995). 
Moreover, a recent meta-analysis suggests that shame is more predictive of depressive symptoms, as assessed by the Center for Epidemiological Studies-Depression scale (Radloff, 1977) and the Beck Depression Inventory (Beck, Steer, \& Brown, 1996), than is guilt (Kim, Thibodeau, \& Jorgensen, 2011). The self-hatred and intense self-criticism that characterize shame not only promote anxiety, depression, and suicidal ideation, but may also play a role in self-harm and self-injurious behavior (Brown et al., 2009; Gilbert et al., 2010).

Although shame is thought to be primarily evoked by moral transgressions, the selfhatred that is associated with shame may not be confined to the metaphysical self -- the mind. It may also be linked to the corporeal, bodily self. Gilbert (1997) expanded on the bodily nature of shame by suggesting that shame is an emergent consequence of the innate human desire to be perceived as attractive. According to Gilbert, attractiveness is one factor that determines relative social standing, and shame is an emotional response to the loss of attractiveness and the accompanying loss of social interaction. In support of this link, evidence suggests that shame plays a key role in disorders that involve body image. Parker (2003) suggested that shame plays a crucial role in the manifestations and maintenance of body dysmorphic disorder (BDD). Parker argued that individuals who suffer from BDD are driven by chronic shame to obsessively attend to physical features that they perceive as unflattering (e.g., a crooked nose). The resulting body obsessions can become so intense that the perceived physical flaw turns into an integral component of the individual's self-image such that they become preoccupied with rituals such as looking in the mirror and in extreme cases, body mutilation. Parker further suggested that the shame which accompanies BDD ultimately encourages the secrecy, hiding, and isolation that is associated with body image disorders. Similarly, it has been suggested that shame plays a key role in the onset and maintenance of eating disorders (Goss \& Allan, 2009). 
The role that shame plays in perceptions of physical attractiveness and body image may have important implications for social behavior. Ample evidence indicates that physical attractiveness is predictive of initial likeability and trustworthiness, which affect the formation of both same sex and opposite sex relationships (Friedman, Riggio, \& Casella, 1988; Pratz, 1983). Given the influence of physical attractiveness on social status and the formation of new relationships, the bodily self-criticism, and in extreme cases self-hatred, that can accompany shame may impede social interaction and the human need to belong (Gilbert, 1997). That is, shame may function as a deterrent of social norm violations by encouraging social ostracism.

Belongingness, or the desire for human companionship, is an important human need that motivates behavior (see Baumeister \& Leary, 1995). In fact, the need to belong is so intense that even simple manipulations, such as a video game (i.e., cyberball) in which players are excluded from a virtual ball tossing game, can elicit psychological distress (Williams, 2001; Williams \& Jarvis, 2006). Recent evidence has even demonstrated that the pain of social rejection may have the same neurological roots as physical pain (see Eisenberger, 2012, for a summary). Social rejection may serve a crucial function in the experience of shame. Some researchers have described shame as a felt emotion in which a perceived flaw is thought to elicit social condemnation and potential social rejection (Gausel, Leach, Vignoles, \& Brown, 2012; Lewis, 1972). Indeed, research has shown that individuals who have a stigma or perceived stigma are more likely to approach social interactions with more trepidation and anxiety (Blascovich, Mendes, Hunter, Lickel, \& Kowai-Bell, 2001; Crocker, Major, \& Steele, 1998). Thus, the perceived stigma and bodily obsessions that accompany shame may perform a very specific social function. According to Fessler (2004), the function of shame is to regulate social systems and hierarchies. In fact, he speculates that shame is responsible for the aversive effects of social 
rejection and may ultimately be responsible for encouraging the maintenance of social norms. In support of the relation between shame and social rejection, some research has suggested that recollection of childhood social rejection (e.g., ignoring by parents) is associated with chronic shame in adulthood (Claesson \& Sohlberg, 2002).

Shame has also been described as "maladaptive" because unlike guilt, which promotes prosocial behavioral responses to moral transgressions (e.g., apologizing), shame encourages dysfunctional behaviors (e.g., hiding and avoidance; Ulrich, Berking, \& Burkardt, 2006). For example, one study found that when participants recalled situations in which they felt either ashamed or guilty, they rated avoidant responses (e.g., I wanted to hide) higher for their shame recollections and approach responses (e.g., I wanted to apologize) higher for their guilt recollections (Schmader \& Lickel, 2006). Of course, in excessive levels, both shame and guilt can be considered maladaptive in that they promote negative perfectionism (e.g., fear of failure; Fedewa, Burns, \& Gomez, 2005). However, shame has been largely thought of as the more maladaptive self-conscious emotion because it encourages behavioral avoidance (Niedenthal et al., 1994; Tangney, 1991; Ulrich et al., 2006).

Contrary to the negative stigma that shame has garnered, some theorists maintain that shame performs an important adaptive function. Gilbert (1997) and Fessler (2004) have both suggested that shame plays an integral role in preserving social order (e.g., maintaining social hierarchies). Similarly, others have suggested that shame may perform an important adaptive function in terms of the maintenance of social norms and moral behavior (Tangney \& Stuewig, 2004). Indeed, recent research has shed a different light on the perceivably maladaptive behaviors associated with shame (e.g., avoidance and hiding). The intensive emotional feedback provided by shame may serve as a deterrent for future transgressions (Grasmick, Bursik, \& 
Kinsey, 1991). Additionally, shame can act as a commitment device. Across four studies, de Hooge, Breugelmans, and Zeelenberg (2008) found that endogenous shame (i.e., shame experienced in the presence of a social exchange partner) predicted prosocial behavior (e.g., giving of coins in a 10-coin give some-dilemma). In a related study, they found that shame encouraged approach behavior intended to repair a damaged self-image (de Hooge, Zeelenberg, \& Breugelmans, 2010). However, when shame was controlled, social rejection/condemnation led to less adaptive responses such as defensiveness (e.g., anger; Gausel, Leach, Vignoles, \& Brown, 2012). Accordingly, shame may operate as a mechanism that encourages the individual to proverbially cleanse the self in order to look like a more desirable social interaction partner.

Viewed in this light, avoidance and hiding are behaviors that enable individuals to escape situations that could lead to further damage to the self and allow the individual to make requisite repairs before re-entering a social situation. In the rare cases that shame encourages prosocial behavior (e.g., giving), it is motivated by the need to self-repair and self-protect (de Hooge et al., 2008; de Hooge et al., 2010). In further support of the adaptive value of shame (i.e., encouraging adherence to moral/social norms), some evidence suggests that one of the deficiencies in psychopathy is a lack of shame (Morrison \& Gilbert, 2001). Additionally, Tangney and colleagues (2003) reported that incarcerated individuals exhibit less shame than control subjects (e.g., non-offenders). Together, these results indicate that shame plays a crucial role in the preservation of societal norms and may even be crucial for rehabilitation (Tangney \& Stuewig, 2004).

In summation, shame appears to be a self-evaluative emotion that has evolved to maintain social order (Fessler, 2004; Gilbert, 1998) by encouraging individuals to follow proscribed social norms. If an individual violates a social norm, the moral violation is marked by self-hatred and 
condemnation (Niendthal et al., 1994). Hence, the moral violator is symbolically marked by negative self-evaluations or the perceived negative evaluations by others, thus, making shame the "ugly" emotion (Tangney, 1991). The symbolic marking and self-condemnation that accompany shame serve the purpose of indicating to the self and others that the individual is not fit for social interaction and, thus, may encourage the shamed individual to engage in hiding and selfreparatory behaviors (de Hooge et al., 2008; de Hooge et al., 2010) in an attempt to make oneself fit for social interaction.

\section{Disgust}

Like shame, disgust is a negative moral emotion that involves bodily concerns and has important implications for social behavior. Darwin (1872) originally referred to disgust as "something revolting, primarily in relation to the sense of taste, as actually perceived or vividly imagined" (p. 254). More recently, disgust has been defined as a cross-cultural emotion (Ekman, 1970) that evolved to protect individuals from bodily contamination including the ingestion of contaminated food and parasitic infestation (Curtis \& Biran, 2001; Oaten et al., 2009). More specifically, disgust has been described as a disease-avoidance mechanism and a component of the behavioral immune system (Oaten et al., 2009; Schaller, 2006).

The behavioral immune system (BIS) is a constellation of psychological mechanisms that have evolved to promote disease avoidance (Schaller, 2006). Whereas the function of the biological immune system is to defend the body against pathogens once they have entered the body, the role of the BIS is to encourage the avoidance of situations that could lead to contamination. The BIS promotes prophylactic responses by automatically inducing adaptive affective (e.g., disgust), cognitive (e.g., thoughts of contamination), and behavioral (e.g., 
avoidance) reactions when individuals are exposed to potentially contaminated stimuli (Schaller, 2006).

Disgust is perhaps the most studied BIS mechanism. It can be conceptualized in terms of a mechanism that can be activated (i.e., turned on or off) by a range of sensory information indicative of contamination. This includes gustatory (e.g., sour milk), olfactory (e.g., garbage), auditory (e.g., clearing throat), visual (e.g., vomit), and tactile (e.g., sticky substance) sensory data. For example, Oum, Lieberman, and Aylward (2011) found that participants perceived wet stimuli to be more disgusting than dry stimuli, suggesting that tactile cues can be indicative of perceived contamination.

Although disgust is thought to be an evolved disease-avoidance mechanism that most individuals experience on at least some level, there is significant variation in disgust reactivity across individuals. Thus, like most psychological constructs, disgust sensitivity can also be assessed as a chronic personality trait. Individuals who are sensitive to disgust are preoccupied with thoughts of contamination. They are prone to Type I errors (i.e., perceiving something as a disease threat when it is not) and are hypersensitive to disgusting stimuli. Accordingly, the cost of disgust sensitivity or reactivity is that potentially viable resources will be neglected due to fear of contamination, whereas the benefit will be reduced exposure to disease threats. Some measures that have been used to tap into individual differences in disgust reactivity and contamination concerns include disgust sensitivity (Haidt, McCauley, \& Rozin, 1994; Olatunji et al., 2007; Tybur, Lieberman, \& Griskevicius, 2009), fear of contamination (Burns, Keortge, Formea, \& Sternberger, 1996), and germ aversion (Duncan, Schaller, \& Park, 2009) measures. Some of the individual difference variability in disgust sensitivity can be explained by demographic variables, such as sex and socioeconomic status (SES). Druschel and Sherman 
(1999) demonstrated that there are significant sex differences in disgust sensitivity, such that females are more sensitive to disgust than males. The sex difference is particularly strong in regard to sexual disgust (i.e., disgust toward sexual behavior; Tybur et al., 2009). As sexual disgust varies across the menstrual cycle (Fessler \& Navarrete, 2003), the differences in sexual disgust may have biological roots. Other evidence suggests that SES is also a significant predictor of individual differences variability in disgust sensitivity. Individuals who are lower in SES are more sensitive to purity violations (e.g., disgust and contamination) than those who are higher in SES (Horberg, Oveis, Keltner, \& Cohen, 2009).

Though disgust has been characterized as an "adaptive" psychological mechanism in that it promotes disease avoidance, it is important to keep in mind that the trait can be dysfunctional in both high and low extremes. As is the case with chronic shame, some research suggests that chronic disgust is predictive of a wide range of psychological disorders. Research has linked disgust to neuroticism, which is characterized by anxiety and moodiness (Olatunji, et al., 2008). Moreover, disgust sensitivity is a significant predictor of obsessive compulsive disorder (OCD), as well as spider, blood, and injection phobias (Berle et al., 2012; Tolin, Lohr, Sawchuk, \& Lee, 1997). Disgust has also been linked to social anxiety. Amir and colleagues (2010) found that socially anxious individuals rated disgusted faces more negatively than angry faces. Furthermore, they found that exposure to disgusting faces led to increased activation of the anterior cingulate cortex, the same area of the brain that is associated with the pain of social rejection (Amir et al., 2005).

On the other hand, lacking sensitivity or reactivity to disgusting stimuli can be equally maladaptive. Although those who are less sensitive to disgust may be less likely to miss out on valuable resources, they may be more likely to be exposed to potentially deadly contagions. 
Additionally, just as disgust sensitivity is positively correlated with psychological disorders (e.g., OCD, phobias and social anxiety; Amir et al., 2005; Amir et al., 2010; Berle et al., 2012; Tolin et al., 1997), it is negatively correlated with other psychological dysfunctions. Preliminary research has indicated that disgust is negatively associated with psychopathy (Tybur et al., 2009), which may help explain the social norm violations that often accompany psychopathy. As such, disgust has been linked to morality in several studies.

Disgust has been described as a moral emotion concerning purity related social norms (e.g., taboo; Haidt, 2003). Inducing disgust by exposing participants to varying amounts of fart spray (e.g., none, 4 sprays, or 8 sprays) resulted in increased severity of moral judgments (e.g., reactions to eating a dead family dog; Schnall, Haidt, Clore, \& Jordan, 2008). Conversely, priming cleanliness (i.e., deactivating disgust and contamination concerns) resulted in less severe moral judgments (Schnall, Benton, \& Harvey, 2008). Furthermore, preliminary evidence also indicates that disgust sensitivity is negatively correlated with psychopathy (Tybur et al., 2009), which may explain why psychopaths are prone to moral and social norm violations. In other words, psychopaths may lack the internal moral regulatory system of which disgust is a component and are, therefore, not internally compelled to adhere to societal norms. It is important to note that the interpersonal nature of moral disgust is functionally different than that of interpersonal contempt. Whereas disgust is concerned with the moral appraisal of intentionally malicious acts, contempt is more predictive of moral violations that result from incompetence (Hutcherson \& Gross, 2011).

Disgust is often associated with avoiding potentially contaminated food products or waste material. However, there are other sources of contamination. One of the primary vehicles for disease transmission is other human beings. Although pathogens presumably do not function on 
the same cognitive plane as humans, like other living organisms, their ultimate evolutionary goal is to survive and reproduce (Dawkins, 1976/1989). Pathogens achieve these goals of survival and reproduction by hijacking the bodies of other organisms, commandeering their resources, and using them as a means of transmission (e.g., via sneezing and coughing; Nesse \& Williams, 1994). As a result of the infectious nature of pathogens and their ability to use humans as vehicles for transportation, other human beings are a significant source of contamination. In Diamond's (1997) Guns, Germs, and Steel, he suggests that germs more so than guns and steel enabled the European colonizers to conquer new lands. Indeed, historical evidence suggests that upwards of $95 \%$ of the Native American population were killed via exposure to smallpox and other infectious diseases when Europeans colonized the Americas (Dobyns, 1983).

Given that others are a significant disease vector, it follows that people who pose a significant disease threat should evoke disgust or contamination concerns. Cross-cultural research on disgust elicitors has provided some initial support for this. For example, evidence suggests that many of the cross-cultural elicitors of disgust (e.g., vomit, urine, feces, pus, and blood) share two key features (Curtis, Aunger, \& Rabie, 2004; Curtis \& Biran, 2001). First, they are all sources of contamination, and second, they are byproducts of the body. Furthermore, recent evidence indicates that exposure to people who pose a disease threat (e.g., runny nose) versus a physical threat (e.g., carrying a gun) activate the biological immune system (Schaller, Miller, Gervais, Yager, \& Chen, 2010). Not only can social interactions activate the biological immune system, but the biological immune system can also evoke disgust and contamination concerns. Miller and Maner (2011) found that individuals who had recently been sick were more avoidant of potentially contaminated others (e.g., individuals with disfigurements). 
Moreover, Schaller and Duncan (2007) have argued that the BIS (e.g., disgust and contamination concerns) should encourage individuals to prefer ingroup members over outgroup members because outgroup members pose a greater disease threat (i.e., they may harbor pathogens for which ingroup members have no immunity). Indeed, evidence has begun to accumulate suggesting that individual differences in disgust sensitivity and contamination concerns, as well as inducing disgust and disease threat, are predictive of avoidance of and negativity toward outgroup members. Faulkner and colleagues (2004) found that trait-level contamination concerns (e.g., perceived infectability) and inducing contamination concerns (e.g., exposing participants to a disease threat) increased negativity toward foreigners (i.e., immigrants). Similarly, Navarrete and Fessler (2006) found individual differences in disgust sensitivity were positively correlated with attitudes toward ingroup members (e.g., Americans) and negatively correlated with outgroup members (e.g., foreigners). Subsequently, individual differences and activation of disgust and contamination concerns have been linked to avoidance of and prejudice toward a wide range of outgroup members including individuals who are obese, disabled, or sexual minorities (Inbar, Pizarro, Knobe, \& Bloom, 2009; Olatunji, 2008; Park, Faulkner, \& Schaller, 2003; Park, Schaller, \& Crandall, 2006; Terrizzi, Shook, \& Ventis, 2010). Disgust and fear of contamination may have more wide sweeping implications for social interactions than merely promoting outgroup avoidance and negativity. In his book, The Anatomy of Disgust, Miller (1997) describes disgust as "one of our more aggressive culturecreating passions" (p. xii). That is, disgust may play a significant role in the construction of social norms, rank, and hierarchies. Indeed, disease avoidance has played an important role in the emergence of culture. For example, some evidence indicates that historical rates of disease prevalence are predictive of social conformity (e.g., right handedness) and collectivism (Fincher, 
Thornhill, Murray, \& Schaller, 2008; Murray, Trudeau, \& Schaller, 2011). Furthermore, the relation is partially mediated by genetic variation, suggesting that the genes that encourage disease avoidance also encourage social conservatism (e.g., adherence to social norms and collectivism; Chiao \& Blizinsky, 2010).

It has also been suggested that disgust and contamination fears may encourage avoidance of potentially contaminated outgroup members by encouraging the formation of socially conservative value systems that promote adherence to social norms and tradition as well as negativity toward and avoidance of outgroup members (Terrizzi et al., 2010; Terrizzi, Shook, \& McDaniel, 2013). Supporting evidence indicates that disgust sensitivity, germ aversion, and fear of contamination are predictive of a wide range of socially conservative value systems (e.g., right-wing authoritarianism, social dominance orientation, religious conservatism, collectivism, and political conservatism; Terrizzi et al., 2013). Additionally, social conservatism (e.g., religious conservatism) mediates the relation between disgust sensitivity and prejudice toward outgroup members (e.g., sexual minorities; Terrizzi, Shook, \& Ventis, 2012). Together, this evidence suggests that disgust plays an important role in shaping social interactions (e.g., prejudice and avoidance) and constructing social value systems (e.g., social conservatism) that are supportive of those interactions. In other words, disgust prepares individuals to perceive others, who may be a source of contamination, negatively and to avoid them.

Like shame, disgust appears to play an important role in social interactions. Both shame and disgust promote avoidance of others but for very different purposes (Oaten et al., 2009; Ulrich et al., 2006). For shame, social avoidance serves to protect the self from the damaging effects of social norm violations (Tangney et al., 2007), whereas for disgust, social avoidance enables disease avoidance (Faulkner et al., 2004; Navarrete \& Fesler, 2006). Indeed, 
considerable evidence suggests that disgust shapes social interactions via the formation of negative attitudes toward other people. However, disgust may not only influence an individual's attitude toward others, it may also have important implications for attitudes toward the self. It may be, for example, that perceiving the self as a source of contamination (i.e., feeling disgusted with the self) results in the experience of shame.

\section{Shame and Disgust}

Some theorists have argued that shame and disgust are linked in that they both involve bodily or self-condemnation, whereas guilt and anger are emotions that involve condemnation of action or behavior (Nussbaum, 2004; Roseman, 1984). Giner-Sorolla and Espinosa (2011) tested whether exposing participants to the social cues of either disgust or anger would result in increased experience of shame and guilt, respectively. Indeed, their study revealed that across two cultures (i.e., the United Kingdom and Spain), participants who were exposed to pictures depicting the facial expression of disgust experienced more shame than guilt, and participants who saw angry faces experienced more guilt than shame.

Another potential link between shame and disgust is the body language and posture that are associated with the two emotions. Darwin (1872) described shame as turning the body away in an attempt to avoid. Similarly, he described the mechanics of disgust as pushing away in an attempt to guard the self. In an empirical examination of emotions and their accompanied posture, Wallbott (1998) found that both shame and disgust involve a collapse of the upper body and downward movement of the head. Both of these behaviors are indicative of making the body a smaller target as if to avoid harm. In the case of shame, the postural change may be an attempt to avoid the stigma that accompanies moral transgression, a symbolic attempt to keep the 
self free of contamination. With disgust, this behavior serves the more practical function of protecting the self from bodily contamination.

In addition to evoking similar bodily postures, both shame and disgust promote a similar broad behavioral pattern (i.e., avoidance). For example, shame has been found to encourage avoidance of social interaction following moral transgression (Schmader \& Lickel, 2006; Ulrich et al., 2006). A similar pattern of behavioral avoidance is observed when individuals are primed with disgust or a disease threat (Faulkner et al., 2004; Navarrete \& Fessler, 2006). Consistent with the postural similarities of shame and disgust, both emotions seem to promote social avoidance, which is consistent with disease avoidance. Further emphasizing the unique relationship between shame and disgust, guilt does not share the same pattern of behavioral avoidance. Instead, guilt is characterized by approach behavior (e.g., apologizing; Schmader \& Lickel, 2006; Ulrich et al., 2006). Furthermore, in the rare cases that shame does promote prosocial approach behavior, the goal of the behavior is not to repair a social relationship but rather it is directed toward repairing the self-image (de Hooge et al., 2008; de Hooge et al., 2010) as if to symbolically cleanse the self.

Shame and disgust seem to also provide similar functions in terms of the maintenance of social norms. For example, both shame and disgust have been defined as moral emotions, which encourage adherence to social norms and moral behavior (Haidt, 2003; Tangney et al., 2007). In support of the role that shame and disgust play in the maintenance of social norms, both have been shown to encourage moral decision making (Schnall et al., 2008; Tangney et al., 2007). Furthermore, deficiencies in both shame and disgust have been associated with psychopathy, which is characterized by an anti-social disregard for social norms (Morrison \& Gilbert, 2001; Tangney et al., 2003; Tybur et al., 2009). 
A final characteristic that both shame and disgust share is concern with the body or the self. The bodily concern that is associated with shame is evinced by its association with body image disorders (e.g., BDD and eating disorders; Gilbert, 1997; Goss \& Allan, 2009; Parker, 2003). Disgust too is concerned with the maintenance of the body in that its primary function is to protect the bodily self from contamination (Oaten et al., 2009). Although shame and guilt are highly confounded, only shame shares a bodily concern with disgust.

One possible explanation for the apparent relation between disgust and shame is that they are overlapping psychological systems. Evolution is a haphazard yet efficient process that takes advantage of existent architecture (Buss, Haselton, Shackelford, Bleske, \& Wakefield, 1998; Marcus, 2008). For example, the feather is thought to be an exaptation, a feature that originally evolved to solve one adaptive challenge but was later co-opted to solve another (Buss et al., 1998). The feather provides an important structural function enabling avian flight, but it is thought to have originally evolved as a means of temperature regulation. Much like the feather now serves a different purpose than the one for which it originally evolved, disgust too may serve a different purpose. That is, in addition to encouraging disease avoidance, disgust may play an important role in the maintenance of social interactions by evoking shame.

Accordingly, shame may be, at least in part, an emergent property of perceiving the self as a source of contamination and disgust. That is, shame may be experienced as disgust with the self. From this perspective, disgust may serve as an internal moral and social regulatory system in that once a social transgression has been perpetrated, the self is perceived as a source of contamination. The stigmatization that accompanies self-disgust and contamination then serves as an internal contingency that can either motivate hiding and avoidance in order to avoid further contamination or prosocial behavior as a means of symbolically cleansing the self. In other 
words, shame may be an emergent property of experiencing disgust with the self, which serves as an internal deterrent of social transgressions.

\section{Current Research}

The goal of the proposed studies was to investigate the role that disgust plays in the selfevaluative emotion of shame. Shame and disgust are thought to have evolved to solve different adaptive challenges (i.e., establishing social hierarchies and disease avoidance, respectively; Curtis et al., 2004; Fessler, 2004; Gilbert, 1997; Oaten et al., 2009). However, the two emotions may be more closely related than previously thought. Both shame and disgust have been described as moral emotions (Haidt, 2003; Schnall et al., 2008; Tangney \& Stuewig, 2004), have similar postural (e.g., shrinking, collapsing, turning away; Darwin, 1872; Wallbott, 1998) and behavioral responses (e.g., avoidance; Oaten et al., 2009 Tangney, 1991), and involve bodily concern (Gilbert, 1997; Goss \& Allan, 2009; Parker, 2003; Oaten et al., 2009). Together, these results suggest that disgust and shame may be overlapping systems.

Little research has investigated the relation between disgust and shame. Consequently, the goal of the current series of studies was to investigate the relation between shame and disgust. Although shame and guilt are often highly confounded (Tangney, 1994), the features that characterize disgust and shame (e.g., bodily concern and social avoidance) do not describe guilt. Therefore, the proposed association between disgust and self-evaluation should specifically result in shame, not general negative self-conscious emotions or guilt. In order to ensure that the relation is indeed unique to the emotions of disgust and shame, guilt and negative affect were included as comparison and control variables.

If shame and disgust share some evolved psychological architecture in which the experience of shame emerges from perceiving the self as a source of contamination and disgust, 
disgust sensitivity and contamination concerns should predict shame proneness. Additionally, if the effect is specific to shame, disgust and contamination concerns should not be correlated with guilt and should remain significant even after controlling for negative affect. Furthermore, if shame is experienced as disgust with the self, there should be a causal relation between the two systems such that inducing disgust should result in increased shame, but not guilt. Likewise, the alleviation of disgust and contamination concerns should result in a reduction of shame, but not guilt. Thus, it was hypothesized that:

$\mathrm{H}_{1}$ : Individual differences in disgust sensitivity and contamination concerns would be positively correlated with shame, but not guilt, propensity.

$\mathrm{H}_{2}$ : Subliminally priming disgust (i.e., subconscious exposure to disgust eliciting words) would increase shame, but not guilt, propensity.

$\mathrm{H}_{3}$ : Subliminally priming purity (i.e., subconscious exposure to purity related words) would decrease shame, but not guilt, propensity.

$\mathrm{H}_{4}$ : Supraliminal exposure to an oral contaminant (i.e., barf flavored jelly bean) would increase shame, but not guilt, propensity.

\section{Study 1}

The purpose of Study 1 was to investigate whether individual differences in disgust sensitivity and contamination fears are associated with individual differences in shame propensity and sensitivity. If shame involves disgust with the self, disgust sensitivity and fear of contamination should be positively correlated with shame. Furthermore, the relation between disgust and shame should not be a mere product of negative affect. In other words, the relation should persist even after controlling for negative mood. Additionally, the relation should be 
specific to shame (i.e., disgust sensitivity and contamination concerns should not be correlated with guilt).

\section{Method}

\section{Participants}

The participants were 195 introductory to psychology students from Virginia Commonwealth University ( $71 \%$ female), who participated in the study online via Sona-systems and received course credit for their participation. They ranged in age from 18 to 47 years-of-age $(M=20.21, S D=3.33)$. Fifty-one percent of the sample was White, $18 \%$ were AfricanAmerican, $14 \%$ were Asian, $4 \%$ were Hispanic, and the remaining $13 \%$ were 'Other' or undisclosed.

\section{Measures and Procedure}

The participants completed a series of questionnaires online via Sona-systems. The questionnaires included measures of disgust sensitivity and contamination fears, shame and guilt proneness, mood, and finally some demographic questions (see Appendix A for all measures).

Disgust and Contamination Measures. General disgust sensitivity was assessed using the Disgust Scale (DS; Haidt et al., 1994; $\alpha=.81$ ). The DS is a 32-item scale. The first 16 items of the disgust scale are scored on a 5 point scale ranging from 0 , strongly disagree, to 5 , strongly agree (originally assessed as true/false). The remaining 16 items are scored on a 5 point scale ranging from 0 , not disgusting at all, to 5, extremely disgusting (originally assessed on a 3 point scale). DS scores were computed by taking the average of the 32 items. An example item from the scale is "I might be willing to try eating monkey meat, under some circumstances."

Pathogen, sexual, and moral disgust sensitivities were measured using the Three Domain Disgust Scale (TDDS; Tybur et al., 2009). The scale contains 21 items measured on a 7 point 
scale ranging from 0 , not at all disgusting, to 6, extremely disgusting. Scores for each of the subscales were calculated by taking the arithmetic average of the items belonging to each of the subscales. Example items include "stepping on dog poop" (pathogen, $\alpha=.83$ ), "hearing two strangers have sex" (sexual, $\alpha=.86$ ), and "shoplifting a candy bar from a convenience store" (moral, $\alpha=.89$ ).

The Disgust Propensity and Sensitivity Scale-Revised was used to assess disgust reactivity (van Overveld et al., 2006; $\alpha=.89$ ). The DPSS-R is a 16 -item scale which contains two 8 -item subscales, one for disgust propensity $(\alpha=.78$ ) and one for disgust sensitivity ( $\alpha=$ .79). The propensity subscale assesses how easily an individual's disgust reaction is triggered whereas the sensitivity subscale measures the emotional intensity of the reaction. The responses range from 1, never, to 5, always. Scores for the Disgust Propensity and Sensitivity subscales were calculated by computing the item averages for the subscales. Example items include "I screw up my face in disgust" (Propensity) and "Disgusting things make my stomach turn" (Sensitivity).

Fear of contamination was assessed using the contamination obsessions and washing compulsions subscale of the Padua Inventory (PI-COWC; Burns et al. 1996; $\alpha=.85$ ). The PICOWC is a 10-item (e.g., "I find it difficult to touch garbage or dirty things.") subscale. Participants indicate the extent to which they experience each statement on a scale from 0 (not at all) to 4 (very much). The PI-COWC score was calculated by taking the arithmetic average of the items.

Shame and Guilt Measures. The Test of Self-Conscious Affect (TOSCA; Tangney \& Dearing, 2002) was used to measure shame and guilt proneness ( $\alpha=.77 \& .78$, respectively). Participants read 15 scenarios and rated the extent to which they would respond in a shameful or 
guilty manner. As with the previous measures, item averages were created for the guilt and shame subscales of the TOSCA. An example scenario includes "At work, you wait until the last minute to plan a project and it turns out badly."

The Guilt and Shame Proneness Scale (GASP; Cohen et al., 2011; $\alpha=.79$ ) is a 20-item scale, and responses to the items range from 1, very unlikely, to 7, very likely. The GASP contains two 5-item subscales of shame and two 5-item subscales of guilt. The shame subscales include a measure of Negative-Self-Evaluation, which assesses global self-condemnation (i.e., negative attitudes toward the self), and a measure of Withdrawal, which assesses an individual's desire to avoid contact with other people following a moral or social contract violation. The guilt subscales include a measure of Negative-Behavior-Evaluation, which assesses behavior condemnation (i.e., negative attitudes toward moral or social contract violations), and a measure of Repair, which assesses the likelihood of prosocial behavior following a moral or social contract violation (e.g., apologize or making amends). For each of the guilt and shame subscales, item averages were computed.

Control Measure. Mood was controlled for using the Positive and Negative Affect Schedule (PANAS; Watson et al, 1988). The scale is composed of twenty adjectives, 10 positive adjectives (e.g., interested; $\alpha=.90$ ) and 10 negative adjectives (e.g., upset; $\alpha=.87$ ). For each adjective, the participants are asked to rate how much they feel it on a 5 point scale, 1 being not at all and 5 being extremely. Item averages were computed for the positive and negative affect subscales.

Demographics. Additionally, participants were asked basic demographic information including age, sex, and ethnicity (see Appendix A).

\section{Results}


Descriptive Statistics and Reliability. All variables were assessed for normality (i.e., skewness and kurtosis) and were relatively normally distributed. The means, standard deviations, and reliabilities for all measures are presented in Table 1.

Zero-Order Correlations. Zero-order correlations for all measures can be found in Table 2. The zero-order correlations were examined to identify general patterns rather than to point out the significance of individual correlations. As expected, the measures of disgust sensitivity and fear of contamination were consistently positively correlated with the measures of shame ( $r$ s ranging from .13 to .49). Additionally, disgust and fear of contamination were positively related to guilt, although these correlations were not consistent across measures. Guilt was consistently correlated only with sexual disgust $(r \mathrm{~s}=.13-.38)$ and moral disgust $(r \mathrm{~s}=.30$ .36). The shame and guilt measures were highly intercorrelated $(r s=.33 \& .57)$. Negative affect was significantly positively correlated with some of the measures of disgust (i.e., the DPSS-R subscales; $r \mathrm{~s}=.17 \& .21$ ), but not correlated with other measures (i.e., DS and TDDS; $r \mathrm{~s}=.01$ .06). Negative affect was not significantly correlated with shame ( $r s=.06 \& .14)$, but the correlations were in the anticipated directions and some were approaching significance. Unexpectedly, negative affect was negatively correlated with guilt $(r \mathrm{~s}=-.16 \&-.17) .{ }^{1}$ Positive affect was not significantly correlated with any of the measures of disgust $(r \mathrm{~s}=-.01-.07)$ or shame $(r \mathrm{~s}=-.05 \&-.10)$. It was, however, significantly positively correlated with guilt $(r \mathrm{~s}=.13$ $\& .18)$.

Partial Correlations. In order to ensure that the relation between shame and disgust was specific to shame, guilt and negative affect were partialled out of the correlations. Additionally, separate analyses were conducted to examine the relation between guilt and disgust. For those 
analyses, both shame and negative affect were partialled out of the correlations. The partial correlations are presented in Table $3 .^{2}$

As hypothesized, disgust sensitivity and fear of contamination were positively correlated with shame even after controlling for guilt and negative affect. The only measure of disgust that was not correlated with shame was moral disgust. These results suggest that the relation between disgust and shame involves physical or bodily contamination rather than symbolic moral contamination. Interestingly, the Negative Self-Evaluation subscale of the GASP, which assess global self-condemnation (i.e., negative attitudes toward the self), was the only indicator of shame that was not significantly correlated with disgust and fear of contamination. On the other hand, disgust and fear of contamination were strongly correlated with the Withdraw subscale, which assesses an individual's desire to avoid situations that could induce shame (i.e., social contract or moral violations). These results suggest that disgust may play an important role in the motivational processes that are involved in avoiding situations that can cause shame. In other words, people may be encouraged to avoid contact with others following a moral or social contract violation because of the risk of being perceived as a source of contamination. This interpretation is consistent with Giner-Sorolla and Espinosa's (2011) work, which suggests that perceiving disgusted faces as opposed to angry faces induces feelings of shame.

Guilt was not consistently correlated with the disease-avoidance components of disgust (i.e., core/pathogen and sexual disgust) and fear of contamination, when controlling for shame and negative affect. However, guilt was consistently positively correlated with moral disgust. Although this finding was not hypothesized, it is consistent with the literature which describes guilt as a moral emotion that is concerned with social contract violations (Tangney et al., 2007).

\section{Discussion}


Study 1 provided initial correlational evidence that there is a unique relation between disgust and shame. Disgust and fear of contamination were consistently positively correlated with shame even after controlling for guilt and negative affect. However, guilt was generally not correlated with the disease-avoidant components of disgust and contamination. These findings provided partial evidence that shame may involve disgust. Nevertheless, Study 1 was limited in that it was a correlational design and therefore unable to provide any evidence for a causal relation between disgust and shame.

Additionally, Study 1 provided some evidence that moral disgust as opposed to the other disgust sensitivity measures (i.e., pathogen/core disgust and sexual disgust) was consistently positively correlated with guilt propensity even after controlling for shame propensity and negative affect. Interestingly, moral disgust was the only measure of disgust sensitivity that was not correlated with shame propensity. This finding is consistent with the primary distinction between shame and guilt (i.e., that shame is characterized by self-evaluation whereas guilt is characterized by behavioral-evaluation; Niedenthal et al., 1994). As moral disgust is a behavioral-evaluation (i.e., how disgusted an individual is by social contract violations), it makes sense that moral disgust was correlated with guilt proneness but not shame proneness.

\section{Study 2}

The purpose of Study 2 was to extend the findings of Study 1 by testing a causal model in which inducing disgust increases shame. If shame is an emotional experience that emerges from feeling disgust with the self and perceiving the self as a source of contamination, inducing disgust should trigger shame. More specifically, it was hypothesized that inducing disgust via a subliminal prime would increase shame propensity and sensitivity. Again, the effect was hypothesized to be specific to shame, so the disgust induction was not expected to affect feelings 
of guilt. Moreover, the effect was expected to be specific to disgust and not the result of general negative affect. That is, it was hypothesized that inducing disgust would result in more shame than both a neutral condition and a condition in which a negative mood state was induced.

\section{Method}

\section{Participants}

The participants were 175 introductory to psychology students from Virginia Commonwealth University ( $62 \%$ female) who received course credit for their participation. They ranged in age from 18 to 41 years-of-age $(M=19.29, S D=2.61)$. Forty-seven percent of the sample was White, $25 \%$ were African-American, $17 \%$ were Asian, $6 \%$ were Hispanic, and the remaining $5 \%$ were 'Other' or undisclosed.

\section{Measures and Procedure}

Upon arriving at the lab, participants completed an informed consent form. Next, they completed the priming task, which was masked as a lexical decision task. Following the priming task, the participants completed the same battery of questionnaires that was used in Study 1, with the addition of the Perceived Vulnerability to Disease (PVD) scale (Duncan et al., 2009; see Appendix A). First, participants completed the measures of shame and guilt, followed by the disgust and contamination measures, then the PANAS, and lastly the demographic questions. Finally, the participants were debriefed. They were told what the true purpose of the study was (i.e., examining the relation between shame and disgust) and they were also informed that the purpose of the deception was to ensure that their responding was not influenced by an awareness of the study's true purpose. Finally, they were given credit and thanked for their participation.

Subliminal Priming. The priming procedure was accomplished through a lexical decision task. The participants were introduced to the lexical decision task as a word game. 
They were told that the purpose of the word game was to assess their ability to recognize words. They were presented with strings of letters and asked to indicate as quickly as possible whether each string of letters was a word or nonword. Prior to each letter string, participants were subliminally primed with either neutral, negative, or disgusting words.

Following the procedure used by Dijksterhuis and colleagues (2008), each trial included a 50ms premask (XXXXXX), a 17ms prime, a 50ms postmask (XXXXXX), and the target string of letters. For half of the trials, the target word was a random string of letters (e.g., "tsers"). The remaining trials contained a neutral word (e.g., book). Participants were randomly assigned to one of three conditions (i.e., disgust, negative, or neutral). Each condition contained 10 primes and each prime was repeated 5 times for a total of 50 trials.

The priming words were matched as closely as possible for length (i.e., number of letters) and starting letter. For the disgust condition, participants were primed with words that evoke bodily disgust (e.g., diarrhea, urine). The participants in the negative condition were primed with words that evoke negativity (e.g., disappointing, useless). Finally, those in the neutral condition were primed with words that do not evoke an emotional response (e.g., door, unit). See Appendix B for the complete list of words that were used for the priming procedure.

Disgust and Contamination Concerns. Since disgust sensitivity has been shown to predict reactivity to disgusting stimuli (van Overveld et al., 2010), there was reason to believe that the efficacy of the disgust manipulation might depend on individual difference in disgust sensitivity and contamination concerns. Thus, participants completed measures of disgust sensitivity and fear of contamination. The DS (Haidt et al., 1994) and the TDDS (Tybur et al., 2009), which were used in Study 1, were used to assess disgust sensitivity. 
Additionally, the Perceived Vulnerability to Disease (PVD) scale was used to assess germ aversion $(\alpha=.74)$ and perceived infectability ( $\alpha=.87$; Duncan et al., 2009). The scale contains two subscales, an 8-item measure of germ aversion (e.g., "I prefer to wash my hands pretty soon after shanking someone's hand.") and a 7-item measure of perceived infectability (e.g., "If an illness is 'going around,' I will get it."). Participants were asked to respond to items on a 7-point scale, 1 being strongly disagree and 7 being strongly agree. Item averages were calculated for the perceived infectability and germ aversion subscales.

Shame and Guilt Measures. Shame and guilt were assessed using the same measures as Study 1, the TOSCA (Tangney \& Dearing, 2002) and the GASP (Cohen et al., 2011).

Control Measures. Mood was controlled for using the PANAS (Watson et al., 1988). Finally, participants were asked basic demographic information (e.g., age, sex, ethnicity).

Manipulation Check. An additional item was added to the PANAS as a manipulation check. Participants were asked how disgusted they felt on a 5-point scale from 1 (not at all) to 5 (extremely).

\section{Results}

Descriptive Statistics and Reliability. All variables were assessed for normality (i.e., skewness and kurtosis) and were relatively normally distributed. The means, standard deviations, and reliabilities for all measures are presented in Table 4.

Manipulation Check. There were no differences in self-reported disgust across the three conditions, $F(2,172)=0.95, p>.05$. Participants in the neutral $(M=1.31, S D=.73)$, negative $(M=1.50, S D=.93)$, and disgust $(M=1.33, S D=.70)$ conditions reported comparable levels of disgust. However, the PANAS, which included the disgust manipulation check, was the last 
measure that the participants completed. The effect of the manipulation may have worn off prior to completion of the manipulation check.

Primary Analyses. The data were analyzed using hierarchical multiple regression following the procedure outlined by Aiken and West (1991). As there were multiple, highly correlated indicators of disgust sensitivity, shame, and guilt, composites variables were created for each of the constructs. ${ }^{3}$ The disgust sensitivity composite was created by standardizing and taking the average of all of the disease-avoidance components of disgust (i.e., DS, TDDSPathogen, TDDS-Sexual, and the Germ Aversion subscale of the PVD; $r \mathrm{~s}=.36-.69)$. Likewise, indexes of shame and guilt were created by standardizing and averaging their respective subscales from the TOSCA and GASP ( $r=.65$ for shame measures, $r=.73$ for guilt measures). Two dummy coded condition variables were created following the steps outlined in Aiken and West (1991). For the first dummy coded variable, the disgust and negative conditions were coded as 0 and the neutral condition was coded as 1 , which tested the main effect of the disgust manipulation relative to the neutral condition. For the second dummy coded variable, the disgust and neutral conditions were coded as 0 and the negative condition was coded as 1 , which tested the main effect of the disgust manipulation relative to the negative condition. As both of these dummy coded variables shared the contrast between the negative and neutral conditions, that effect was partialled out.

In order to ensure that the effect was not due to a general state of negative mood, the negative affect subscale of the PANAS was entered in the first step of the regression model. The dummy coded condition variables and the disgust sensitivity composite were entered in the second step of the analysis. Finally, interaction terms between the condition and the disgust sensitivity composite variables was created by standardizing the disgust sensitivity variable and 
multiplying it by each condition variable. These interaction terms were added into the third step of the hierarchical regression model.

Shame as the Dependent Variable. There was a main effect for the disgust sensitivity composite $\left(\beta=.31, p<.001, R^{2}\right.$ change $=.09$, See Table 5). This replicated the findings of Study 1, suggesting that disgust was positively correlated with shame. As in Study 1, the effect remained significant even when controlling for guilt $(\beta=.15, p=.03)$. There was, however, no main effect for condition. Participants in the disgust condition did not experience more shame than either participants in the neutral condition $(\beta=-.01, p=.95)$ or the negative condition $(\beta=-$ $.01, p=.92)$. There was a significant interaction between the disgust sensitivity composite and condition. The interaction was significant both when the disgust condition was compared to the neutral condition $\left(\beta=-.27, p<.001, R^{2}\right.$ change $\left.=.05\right)$ and the negative condition $(\beta=-.23, p=$ $.02)$. When comparing the disgust condition to the neutral condition, the interaction remained significant even after controlling for guilt $(\beta=-.21, p=.01$ ). When comparing the disgust condition to the negative condition, the interaction became nonsignificant when controlling for guilt $(\beta=-.13, p=.12)$. The interaction is displayed in Figure 1. An analysis of simple slopes indicated that at high levels of disgust sensitivity (i.e., $+1 S D$ ), the disgust manipulation significantly increased shame when compared to the neutral condition $(\beta=.28, p=.03)$. Likewise, at high levels of disgust sensitivity, the manipulation led to a marginally significant increase in shame compared to the negative condition $(\beta=.23, p=.07)$. In other words, for those who were more sensitive to disgust, the disgust manipulation increased shame.

At low levels of disgust sensitivity (i.e., - $1 S D$ ), the disgust manipulation led to a marginally significant decrease in shame compared to the neutral condition $(\beta=-.22, p=.08)$. Likewise, at low levels of disgust sensitivity, the disgust manipulation significantly decreased 
shame compared to the negative condition $(\beta=-.30, p=.02)$. That is, those who were less sensitive to disgust experienced less shame following the disgust induction

Guilt as the Dependent Variable. As the effect of disgust was expected to be specific to shame, the same regression procedure was conducted using guilt as the dependent measure. The results for the guilt analysis indicated that there was a main effect for the disgust sensitivity composite $\left(\beta=.33, p<.001, R^{2}\right.$ change $=.11$, See Table 6$)$. In contrast to Study 1 , the effect remained significant after controlling for shame and negative affect $(\beta=.17, p=.01)$. There was, however, no main effect for condition. Participants in the disgust condition did not experience more guilt than participants in either the neutral $(\beta=-.01, p=.95)$ or the negative condition $(\beta=.06, p=.49)$. There was a significant interaction between disgust sensitivity and condition. The interaction was significant only when the disgust condition was compared to the neutral condition $\left(\beta=-.21, p=.03, R^{2}\right.$ change $\left.=.03\right)$. It was not significant when the disgust condition was contrasted with the negative condition $(\beta=-.12, p=.19)$. More importantly, the interaction became nonsignificant when shame was controlled $(\beta=-.10, p=.27)$.

\section{Discussion}

Although there was no evidence for a main effect of the disgust manipulation, Study 2 provided initial evidence that inducing disgust increased shame for individuals who were sensitive to disgust. These results were significant even after controlling for negative affect and guilt. Moreover, the effect seemed to be particular to shame and disgust. When guilt was analyzed as the dependent variable, there was a significant interaction such that for those who were more sensitive to disgust, the induction increased guilt, but only compared to the neutral condition. Importantly, however, the effect became nonsignificant when shame was controlled, highlighting the unique relationship between shame and disgust. 
Another interesting, but unexpected, finding from Study 2 was that for those low in disgust sensitivity, inducing disgust led to a reduction in shame. One possible explanation for this unanticipated finding is that the participants were not internalizing the disgust reaction as those who are less sensitive to disgust are also less likely to be sensitive to shame. In other words, it may be a contrast effect in which participants less sensitive to disgust were less likely to associate disgust with the self. Thus, self-evaluations may have been more positive in contrast to feelings of disgust induced by the priming procedure.

\section{Study 3}

If the experience of shame stems from perceiving the self as a source of disgust and contamination, reducing disgust and contamination concerns should result in a reduction of shame. Indeed, other researchers have had success priming purity to reverse the effects of disgust. Schnall and colleagues (2008) demonstrated that although priming disgust increases the severity of moral decision making, priming cleanliness (i.e., having participants wash their hands) encouraged less severe moral reactivity. Thus, the primary purpose of Study 3 was to evaluate whether subliminally priming purity would result in decreased shame propensity and sensitivity. Priming was accomplished using the same lexical decision task as Study 2, with the addition of two conditions (i.e., purity and positivity). The positivity prime was included in order to ensure that any effect was specific to purity and not simply due to positivity. A secondary goal of Study 3 was to replicate the findings of Study 2 in a different sample (i.e., WVU students). In other words, it was hypothesized that for those who are sensitive to disgust, subliminally inducing disgust would increase shame propensity and sensitivity compared to both negative and neutral conditions, whereas subliminally inducing purity would decrease shame propensity and sensitivity compared to both positive and neutral conditions. 


\section{Method}

\section{Participants}

The participants were 272 introductory to psychology students from West Virginia University (68\% female) who received course credit for their participation. They ranged in age from 18 to 37 years-of-age $(M=19.88, S D=2.62)$. Eighty-five percent of the sample was White, $7 \%$ were African-American, 3\% were Asian, 2\% were Hispanic, and the remaining 3\% were 'Other' or undisclosed.

\section{Procedure}

The procedure for Study 3 was virtually identical to Study 2 except for the addition of two subliminal priming conditions (i.e., purity and positive). As in the previous studies, participants first completed an informed consent form. Following the consent procedure, participants completed the lexical decision task as outlined in Study 2. Participants were randomly assigned to either a purity, positive, disgust, or neutral condition. In the purity condition, the primes were related to cleanliness (e.g., clean, pure). In the positive condition, the primes were evocative of positivity (e.g., happy, joy). For the disgust, negative, and neutral conditions, the primes were the same as those that were used in Study 2. See Appendix B for a complete list of the priming words.

After the participants finished the lexical decision task, they completed the same series of questionnaires that were used in Study 2 (see Appendix A for the complete measures). Disgust and contamination concerns were assessed using the DS (Haidt et al., 1994), TDDS (Tybur et al., 2009), DPSS-R (van Overveld et al., 2006), the PI-COWC (Burns et al., 1996) and the PVD (Duncan et al., 2009). Shame and guilt were measured using the TOSCA (Tangney \& Dearing, 2002) and the GASP (Cohen et al., 2011). Mood was controlled for using the PANAS (Watson 
et al., 1988). A disgust item was imbedded in the PANAS as a manipulation check. Lastly, participants were asked basic demographic information (e.g., age, sex, ethnicity etc.). As in Study 2, upon completing the study participants were informed of the true purpose of the research (i.e., examining the relation between shame and disgust). They were debriefed about the subliminal prime and told that the purpose of the deception was to ensure that the knowledge of the study did not influence their responses. Finally, they were given credit and thanked for their participation.

\section{Results}

Descriptive Statistics and Reliability. All variables were assessed for skewness and kurtosis and were relatively normally distributed. Means, standard deviations, and Cronbach's alphas for all measures are presented in Table 7.

Manipulation Check. There were no differences in self-reported disgust across the five conditions, $F(4,267)=0.96, p>.05$. Participants in the neutral $(M=1.20, S D=.59)$, negative $(M=1.18, S D=.60)$, disgust $(M=1.35, S D=.77)$, positive $(M=1.20, S D=.49)$, and purity $(M$ $=1.15, S D=.45$ ) conditions reported comparable levels of disgust. As in Study 2, the manipulation check was imbedded in the PANAS, which was the last measure that participants completed. The effect of the manipulation may have worn off prior to completion of the manipulation check.

Comparison of all Conditions. As in the previous study, composite variables were created for disgust, shame, and guilt. The indicators for each of the respective constructs were highly intercorrelated and the primary analyses that were conducted were relatively consistent across each individual indicator. Thus, only the analyses with the composite variables are reported. Participant sex also did not affect the results of the analyses. The composite variables 
for disgust (i.e., DS, TDDS-Pathogen, TDDS-Sexual, DPSS-R, and the Germ Aversion subscale of the PVD; $r \mathrm{~s}=.22-.72$ ), shame (i.e., the shame subscales of the TOSCA and GASP, $r=.58$ ), and guilt (i.e., the guilt subscales of the TOSCA and GASP, $r=.63$ ) were constructed by standardizing and averaging the measures for each of the constructs.

First, separate ANCOVAs were conducted to evaluate whether the manipulation had an effect on shame or guilty. Negative affect and disgust sensitivity were included as covariates. There was no evidence of a main effect for the shame analysis, $F(4,265)=2.14, p>.05$. Participants in the Neutral $(M=.18, S D=.98)$, Negative $(M=.03, S D=.99)$, Disgust $(M=-.22$, $S D=.96)$, Positive $(M=.12, S D=.98)$, and Purity $(M=-.14, S D=1.06)$ conditions reported comparable levels of shame. Additionally, there was no evidence of a main effect for the guilt analysis, $F(4,265)=1.53, p>.05$. Participants in the Neutral $(M=.06, S D=1.04)$, Negative $(M$ $=.09, S D=.84)$, Disgust $(M=-.16, S D=1.15)$, Positive $(M=.19, S D=.78)$, and Purity $(M=-$ $.19, S D=1.18)$ conditions reported comparable levels of guilt.

In order to test for interactions between the manipulations and disgust sensitivity, the data were analyzed using hierarchical multiple regression following the same procedure that was outlined in Study 2 (see Aiken \& West, 1991). For ease of interpretation and in order to address the study hypotheses, separate analyses were conducted examining purity as the comparison variable (i.e., comparing the purity condition to the neutral and positive conditions) and disgust as the comparison variable (i.e., comparing the disgust condition to the neutral and negative conditions). Likewise, separate analyses were conducted examining shame and guilt as dependent variables. When purity was the comparison condition, a dummy variable was created in which purity and positivity were coded as 0 and neutral was coded as 1 , and a second dummy coded variable was created in which purity and neutral were coded as 0 and positivity was coded 
as 1 . The same procedure was followed when disgust was examined as the comparison condition. Two dummy coded variables were created, one in which disgust and negative were coded as 0 and neutral was coded as 1 , and another variable in which disgust and neutral were coded as 0 and negative was coded as 1 . For all of the analyses, negative affect was entered in step one as a control variable, the disgust sensitivity composite and the dummy coded variables were entered in step two, and finally, the interaction terms (i.e., disgust sensitivity composite $\mathrm{x}$ dummy variables) were entered in step three.

Analysis of Purity Induction. When shame was explored as the dependent variable, there was a main effect for the disgust sensitivity composite $\left(\beta=.51, p<.01, R^{2}\right.$ change $=.26$, See Table 8), which remained significant when controlling for guilt $(\beta=.43, p<.01)$. There was no main effect for condition. That is, the purity manipulation did not decrease disgust compared to either the neutral $(\beta=.10, p=.17)$ or positive $(\beta=.11, p=.15)$ conditions. The interaction between condition and disgust sensitivity was also not significant when the purity condition was compared to the neutral condition $\left(\beta=-.03, p=.71, R^{2}\right.$ change $\left.=.01\right)$ or the positive condition $(\beta$ $=-.13, p=.18)$.

When guilt was the dependent variable, there was a main effect for the disgust sensitivity composite $\left(\beta=.32, p<.01, R^{2}\right.$ change $\left.=.12\right)$. The effect became nonsignificant when controlling for shame ( $\beta=.03, p=.75)$. There was no main effect for condition when the purity condition was compared to the neutral condition $(\beta=.08, p=.37)$. There was, however, a main effect when the purity condition was compared to the positive condition (i.e., the purity condition did experience less guilt than the positive condition; $\beta=.17, p=.05$ ). The effect became nonsignificant when shame was controlled $(\beta=.11, p=.15)$. There was no evidence of an interaction. The interaction between the manipulation and the disgust sensitivity composite was 
nonsignificant both when the purity condition was compared to the neutral condition ( $\beta=.05, p$ $=.62, R^{2}$ change $\left.=.00\right)$ and the positive condition $(\beta=.02, p=.86)$.

Analysis of Disgust Induction. For the shame analysis, there was a main effect for the disgust sensitivity composite $\left(\beta=.47, p<.01, R^{2}\right.$ change $=.25$, See Table 9$)$. This replicated the findings of both Studies 1 and 2, suggesting that disgust was positively correlated with shame. As in the previous studies, the effect remained significant when controlling for guilt ( $\beta=.42, p<$ .01). There was also a main effect for condition. However, the effect was in the opposite direction as hypothesized. Participants in the disgust condition experienced less shame than both the participants in the neutral $(\beta=.18, p=.02)$ and negative conditions $(\beta=.15, p=.05)$. The main effect for disgust compared to the negative condition remained significant $(\beta=.16, p=.04)$ even after controlling for guilt. When compared to the neutral condition, it was nonsignificant ( $\beta$ $=.12, p=.12$ ) after controlling for guilt. Unlike Study 2, there was no evidence of an interaction. The interaction was nonsignificant both when the disgust condition was compared to the neutral condition $\left(\beta=.08, p=.38, R^{2}\right.$ change $\left.=.00\right)$ and the negative condition $(\beta=.05, p=$ $.61)$.

For the guilt analysis, there was a main effect for the disgust sensitivity composite ( $\beta=$ $.32, p<.01, R^{2}$ change $=.12$ ). However, as in Study 1, the effect became nonsignificant when shame was controlled $(\beta=.04, p=.64)$. There was no main effect of the disgust induction when compared to either the neutral $(\beta=.10, p=.28)$ or negative conditions $(\beta=.13, p=.15)$. There was also no evidence of an interaction when the disgust condition was compared to the neutral condition $\left(\beta=-.04, p=.97, R^{2}\right.$ change $\left.=.05\right)$. There was evidence of an interaction when the disgust condition was compared to the negative condition $(\beta=-.26, p=.01)$. The interaction suggested that for those who were less sensitive to disgust, those in the negative condition 
experienced more guilt than those in the disgust condition, but for those who were more sensitive to disgust, those in the disgust condition experienced more guilt than those in the negative condition. The interaction remained significant even after controlling for shame ( $\beta=-.27, p<$ $.01)$.

\section{Discussion}

Although the effect of the purity manipulation was in the predicted direction (i.e., participants in the purity condition experienced less shame compared to the positive and neutral conditions), the effect was not significant. Thus, it appears that subliminally priming purity did not decrease explicitly (i.e., consciously) reported shame sensitivity and propensity. One potential explanation for the ineffectiveness of the purity prime may be that the prime was too weak to reduce the participants' baseline disgust sensitivity levels. A more effective purity manipulation may have been to have participants wash their hands, which has previously been shown to reduce disgust (Schnall et al., 2008).

Furthermore, the main effect of the disgust manipulation resulted in the opposite effect of what was anticipated. Those in the disgust condition experienced less shame compared to the neutral and negative conditions. This was in direct contrast with the correlations across Studies 1,2 , and 3 , which consistently suggested that disgust sensitivity was positively correlated with shame propensity-. Moreover, it was in contrast to the interaction in Study 2, which suggested that inducing disgust increased shame for those who were more sensitive to disgust. It is unclear why the results of Study 3 were in stark contrast to Study 2.

One possible explanation may lie in the environment in which the experiments took place. Study 2 took place at Virginia Commonwealth University (VCU) and the sessions were conducted in group setting (i.e., participants completed the study in an environment in which 
other participants were present). Study 3 took place at West Virginia University (WVU) and the participants completed the study in private rooms (i.e., participants completed the study alone). The reason that this variation may have played a key role in that public exposure may be necessary for shame to take place (see Tangney et al., 2007). That is, other people are required to be present in order for shame to be induced.

Another possible explanation for the inconsistencies between Studies 2 and 3 is that different samples were used (i.e., VCU vs WVU). It is, however, not clear what role the difference in samples would have played in these divergent results. When the means and standard deviations for the VCU and WVU samples were compared, they were very similar suggesting that there is little reason to believe that the samples differ in terms of disgust sensitivity or shame proneness.

\section{Study 4}

The purpose of Study 4 was to evaluate whether a more ecologically valid manipulation (i.e., a form of disgust that one might encounter in everyday life) would increase shame propensity and sensitivity. As disgust is generally thought to function as a disease-avoidance mechanism that promotes avoidance of potentially contaminated food (Oaten et al., 2009) and is thought to be intimately linked to the senses of taste and smell, in Study 4, disgust was induced directly via the gustatory route. More specifically, half of the participants consumed a disgusting flavored (e.g., barf) jelly bean whereas the other half ate a regularly flavored (e.g., peach) jelly bean. As in the previous studies, negative affect and guilt were controlled. It was hypothesized that those who consumed the disgusting flavored jelly beans would exhibit more shame than those who ate the pleasant flavored jelly beans.

\section{Method}




\section{Participants}

The participants were 181 introductory to psychology students from West Virginia University (68\% female) who received course credit for their participation. They ranged in age from 18 to 39 years-of-age $(M=19.55, S D=2.48)$. Eighty-four percent of the sample was White, 5\% were African-American, 3\% were Asian, 3\% were Hispanic, and the remaining 4\% were 'Other' or undisclosed.

\section{Measures and Procedure}

Upon arriving at the lab, participants first completed an informed consent form. Once the consent form was completed, they participated in what they believed to be a taste test in which they were asked to describe how several jelly beans tasted and rate their pleasantness. The pleasantness ratings of the jelly beans were averaged and used as a manipulation check. The real objective of the taste test, however, was to experimentally induce disgust. Participants were randomly assigned to either disgusting flavored jelly beans (i.e., barf) or regularly flavored jelly beans (i.e., peach). The unpleasantly flavored jelly beans are manufactured by JellyBelly as part of their Harry Potter and Bean Boozled collections. They are visually indistinguishable from the regularly flavored jelly beans. After eating the jelly beans, the participants were asked to describe the taste of the jelly beans in a brief essay and then rate the taste of the jelly beans (e.g., how much do you like the jelly bean?, how good do the jelly beans taste?).

Once the participants completed the taste test, they were asked to complete a series of questionnaires. The same measures from Studies 2 and 3 were used (see Appendix A for complete measures). Disgust and contamination concerns were assessed using the DS (Haidt et al., 1994), TDDS (Tybur et al., 2009), DPSS-R (van Overveld et al., 2006), the PI-COWC (Burns et al., 1996) and the PVD (Duncan et al., 2009). Shame and guilt were assessed with the 
TOSCA (Tangney \& Dearing, 2002) and the GASP (Cohen et al., 2011). Mood was controlled for using the PANAS (Watson et al., 1988). As in Studies 2 and 3, a disgust item was embedded in the PANAS as a manipulation check. For an additional manipulation check, participants were asked to report how disgusted they were by the jelly bean on a scale from 1 (not disgusted at all) to 7 (very disgusted). Lastly, participants were asked some basic demographic information (e.g., age, sex, ethnicity). Upon completion of the study, participants were informed of the true nature of the study, given research credit, and thanked for their participation.

\section{Results}

Descriptive Statistics and Reliability. All variables were assessed for skewness and kurtosis and were relatively normally distributed. Means, standard deviations, and Cronbach's alphas for all measures are presented in Table 10.

Manipulation Check. Participants in the disgust condition (i.e., barf flavored jelly bean) found the jelly bean more unpleasant $(M=5.80, S D=1.19)$ than those in the control condition $(M=2.27, S D=1.33), t(179)=18.78, p<.01$. Additionally, participants in the disgust condition $(M=5.10, S D=1.82)$ reported being more disgusted by the jelly bean than the control group $(M=1.38, S D=.86), t(179)=-17.44, p<.01$. There was, however, no difference in selfreported disgust (i.e., the disgust item that was embedded in the PANAS). Those in the disgust condition $(M=1.46, S D=.82)$ reported about the same level of disgust as those in the control condition $(M=1.38, S D=.70), t(179)=-0.77, p=.44$.

Primary Analyses. The data were analyzed following the same procedure as Studies 2 and 3 (i.e., hierarchical multiple regression; see Aiken \& West, 1991). Participant sex did not alter the results of the analyses, so the reported analyses do not include sex as a variable. Separate analyses were conducted for both shame and guilt. As in the previous studies, 
composites were created of disgust, shame, and guilt. The indicators of each of the respective constructs were highly intercorrelated and the primary analyses were relatively consistent across the individual measures. Composite variables for disgust (i.e., DS, TDDS-Pathogen, TDDSSexual, DPSS-R, and the Germa Aversion subscale of the PVD, $r s=.20-.71$ ), shame (i.e., the shame subscales of the TOSCA and GASP, $r=.57$ ), and guilt (i.e., the guilt subscales of the TOSCA and GASP, $r=.68$ ) were constructed by standardizing and averaging the measures for each of the constructs. A dummy coded variable was created for condition in which the disgust condition was coded as 1 and the control condition was coded as 0 . An interaction term was computed by multiplying the disgust sensitivity composite by the dummy coded condition variable. For all of the analyses, negative affect was entered as a control variable in step 1, the disgust sensitivity composite and the condition variable were entered in step 2 , and the interaction term was entered in step 3.

Shame as the Dependent Variable. For the shame analysis, the disgust sensitivity composite emerged as a significant predictor (i.e., disgust was positively correlated with shame; $\beta=.49, p<.01, R^{2}$ change $=.24$, See Table 11). As in the previous studies, this effect remained significant after controlling for guilt $(\beta=.38, p<.01)$. There was no main effect for condition (i.e., the manipulation did not have a significant effect on shame; $\beta=.03, p=.68$ ). There was, however, evidence of a significant interaction between disgust sensitivity and the manipulation $\left(\beta=-.23, p=.01, R^{2}\right.$ change $=.03$; see Figure 2$)$. The interaction remained marginally significant even after controlling for guilt $(\beta=-.16, p=.06)$. An analysis of simple slopes indicated that for those who were less sensitive to disgust (i.e., -1 $S D$ ), the disgust manipulation led to a marginally significant increase in shame $(\beta=.16, p=.07)$. However, for those who 
were more sensitive to disgust (i.e., $+1 S D$ ), the manipulation led to a nonsignificant reduction in shame $(\beta=-.12, p=.19)$.

Guilt as the Dependent Variable. For the guilt analysis, the disgust sensitivity composite emerged as a significant predictor (i.e., disgust was positively correlated with guilt; $\beta$ $=.36, p<.01, R^{2}$ change $\left.=.13\right)$. The correlation was attenuated when controlling for shame $(\beta=$ $.18, p=.02$ ). There was no main effect for condition (i.e., the manipulation did not have a significant effect on guilt; $\beta=.05, p=.48$ ). However, the same interaction that emerged with the shame analysis emerged in the guilt analysis $\left(\beta=-.24, p=.02, R^{2}\right.$ change $\left.=.03\right)$. The interaction became nonsignificant when shame was controlled $(\beta=-.16, p=.10)$. An analysis of simple slopes indicated that for those who were less sensitive to disgust (i.e., -1 SD), the disgust manipulation led to a significant increase in guilt $(\beta=.23, p=.02)$. However, for those who were more sensitive to disgust (i.e., $+1 S D$ ), the manipulation led to a nonsignificant reduction in guilt $(\beta=-.12, p=.19$; see Figure 2).

\section{Discussion}

As in the previous three studies, disgust sensitivity emerged as a significant predictor of shame even after controlling for guilt and negative affect. However, the disgust manipulation did not have a significant effect on shame. Even more perplexing, there was an interaction between disgust sensitivity and the manipulation such that for those who were less sensitive to disgust, the manipulation led to a marginally significant increase in shame. This is in direct contrast to Study 2, in which the disgust manipulation increased shame for those who were more sensitive to disgust. These divergent results may be explained by the nature of the manipulation. In Study 2, the disgust manipulation was subliminal (i.e., unconscious) and thus, the participants may have misattributed the source of their disgust to the self, resulting in increased shame. 
However, in the current study, the manipulation was supraliminal (i.e., conscious). Thus, it may be that in the current study those who were sensitive to disgust attributed the disgust to the jelly bean rather than the self (i.e., shame) because they were aware of the source of their disgust.

\section{General Discussion}

Across all 4 studies, shame and disgust were positively correlated (i.e., those who were sensitive to disgust were sensitive to shame and vice versa). More importantly, in all of the studies, disgust sensitivity was a significant predictor of shame even after controlling for guilt and negative affect, emphasizing that the relation between disgust and shame is unique. That is, the relation between disgust and shame was not due to general negative affect (i.e., that they are both negatively valenced emotions) and the same pattern was not seen with shame's sibling emotion, guilt. Interestingly, however, guilt was consistently positively correlated with sexual and moral disgust even after controlling for shame and negative affect. This effect may be due to the fact shame and guilt differ in regard to the nature of their self-conscious evaluations. For shame, the self is the object of the negative evaluations whereas for guilt, the behavior serves as the attitude-object (Niedenthal et al., 1994). Thus, guilt may be predictive of both moral and sexual disgust because they concern negative behavioral evaluations (i.e., being disgusted by sexual activity and social contract violations).

Study 2 provided some support for a causal relation between disgust and shame. Although there was no main effect for the disgust induction (i.e., inducing disgust did not increase shame for all participants), the disgust manipulation increased shame for individuals who were more sensitive to disgust. However, these findings were not replicated in Study 3. In fact, the findings in Study 3 were in direct contrast with the hypothesis. The disgust manipulation led to a reduction in shame compared to the neutral and negative conditions. The 
methodologies for Studies 2 and 3 were virtually identical, which makes these results puzzling. One potential explanation for this quizzical finding is the context in which the study was conducted. Study 2 was conducted in a group setting (i.e., participants completed the study in the presence of other participants and the experimenter) whereas in Study 3, the participants completed the study alone (i.e., in a private room in the absence of the experimenter and other participants). As the experience of shame is thought to require public exposure (i.e., the presence of others; Tangney et al., 2007), it may be the absence of others in Study 3 inhibited participants from experiencing shame.

If shame is experienced as disgust with the self, then it follows that reducing disgust should reduce shame. The results of Study 3, however, failed to provide evidence that inducing purity would reduce shame. Although the results were in the predicted direction (i.e., participants in the purity condition experienced less shame than those in the neutral and positive conditions), the effect was nonsignificant. Thus, there was no evidence that reducing disgust relieves the experience of shame. Again, the fact that participants completed the study individually in private rooms may have diluted the effect.

Study 4 also provided some puzzling results. Although there was no main effect for the disgust manipulation (i.e., the barf flavored jelly beans did not induce increase shame for all of the participants), there was a significant interaction such that for those who were less sensitive to disgust, the manipulation increased shame. It did, however, not increase shame for those who were more sensitive to disgust. These results were in direct opposition to Study 2, which found that inducing disgust increased shame for those who were more sensitive to disgust. A potential explanation for the conflicting findings of Studies 2 and 4 may be the nature of the manipulation. In Study 2, disgust was manipulated subliminally (i.e., unconsciously), which may help explain 
why disgust increased shame for those who were sensitive to disgust (i.e., they were unaware of the manipulation and thus misattributed the disgust to the self resulting in increased shame). On the other hand, in Study 4, the manipulation was supraliminal (i.e., conscious). In this study, the participants who were more sensitive to disgust may have been more able to identify the jelly bean as the source of the disgust, whereas those who were less sensitive to disgust were not as capable of identifying the source of the disgust. Thus, individuals who were less sensitive to disgust misattributed the disgust to the self which resulted in increased shame. It is still, however, somewhat unclear as to why individuals who were less sensitive to disgust misattributed the disgust to the self in Study 4 but exhibited a contrasting effect in Study 2. This may be partially explained by the route of the manipulation. In Study 4, the manipulation was physically connected to the self (i.e., the self was contaminated via the ingestion of the jelly bean), whereas in Study 2, the self or physical body did not come in contact with the source of contamination. Consequently, there may have been a greater likelihood of attributing disgust to the self in Study 4, particularly for those less sensitive to disgust.

Although the current studies provided consistent correlational evidence that there is a unique relationship between shame and disgust (i.e., shame and disgust sensitvity were consistently positively correlated in all 4 studies even after controlling for negative affect and guilt), the experimental studies resulted in conflicting evidence in terms of the causal relationship between shame and disgust. As a whole, these studies provided initial evidence for the relation between shame and disgust, but it is clear that much more work needs to be done in order to elucidate the exact nature of the relation between shame and disgust.

Limitations and Future Directions. One primary limitation of the current series of studies is that disgust with the self was not directly manipulated. Studies 2, 3, and 4 induced 
disgust, but they did not directly link disgust with self. Future studies should evaluate whether manipulating disgust toward the self (e.g., having participants imagine or recall scenarios in which they got sick in public) results in more consistent findings. If shame is experienced as disgust with the self, manipulations that evoke disgust with self should be more likely to consistently increase shame.

Similarly, none of the studies in the current project directly assessed disgust with the self. The correlations that were reported between shame and disgust only examined disgust propensity and sensitivity. Overton and colleagues (2008) have developed a measure of self-disgust, which contains items like "I find myself repulsive." Future research should incorporate this measure. If shame is experienced as disgust toward the self, self-disgust should be positively correlated with shame.

Additionally, all of the studies assessed shame using explicit measures. Social desirability can be a problem particularly for self-report measures of attitudes toward the self, because people tend to engage in positive illusions (i.e., presenting the self in a more positive light; Oakes, Brown, \& Cai, 2008; Heatherton \& Wyland, 2003). As shame is concerned with negative self-evaluations, this positivity bias could be a problem for the current research because it may make individuals less likely to report shame. Thus, the incorporation of implicit measures may provide a more accurate assessment (i.e., a measure that is not affected by social desirability) of shame. Moreover, implicit measures could be used to assess the extent to which individuals associate disgust with the self. If shame is experienced as disgust with the self, individuals who are sensitive to shame should categorize disgusting adjectives (e.g., repulsive) more quickly than negative adjectives (e.g., unpleasant) following self primes (e.g., I or me). 
Some of the first research linking shame to disgust utilized facial expressions of emotions (Giner-Sorolla \& Espinosa, 2011). Although Giner-Sorolla and Espinosa's research examined self-reported shame following exposure to a facial expression of disgust, an equally interesting approach to analyzing the relation between disgust and shame may be to examine whether priming individuals with disgust results in facial expressions of shame. Some recent research has suggested that there may be some evidence of reliable facial expressions of shame (Widen, Christy, Hewett, \& Russell, 2011). If there is a unique relationship between disgust and shame, publically exposing individuals to a disgusting stimulus should result in facial expressions of shame.

Lastly, although the current studies presented consistent positive correlations between shame and disgust sensitivity, these correlations may be explained by an unmeasured third variable (e.g., behavioral inhibition or neuroticism). Both disgust and shame have been correlated with behavioral inhibition or behavioral avoidance and neuroticism (Cohen et al., 2011; Olatunji et al., 2008; Ulrich et al., 2006). Thus, future research should evaluate whether the relation between disgust and shame persists even after controlling for behavioral inhibition and neuroticism.

Conclusion. Although the results from the studies presented here were somewhat inconsistent, they did provide some evidence for a link between shame and disgust (i.e., shame and disgust sensitivity were consistently positively correlated even after controlling for negative affect and guilt). Though additional work needs to be done in order to understand the causal nature of this relation, it may have some important clinical implications for clients who suffer from shame-related psychological disorders (e.g., body dysmorphic disorder and eating disorders). Indeed, given the accumulation of evidence linking disgust sensitivity with anxiety 
disorders (see Olatunji \& McKay, 2009), some researchers have already proposed reducing disgust sensitivity as a measure of psychotherapy. Some evidence has indicated that habituation to disgust can reduce disgust-related anxiety (Viar-Paxton, \& Olatunji, 2012). If future experimental evidence validates the causal relation between disgust and shame (i.e., if disgust causes shame), these types of disgust reduction therapies may prove to be effective treatments for shame-related psychological disorders. Additionally, if shame is experienced as disgust with the self, it may help shed light on broader issues such as stigmatization (i.e., stigma may be experienced as self-contamination). What is clear, however, is that more research needs to be done to clarify the relation between disgust and shame. 


\section{References}

Aiken, L. S., \& West, S. G. (1991). Multiple regression: Testing and interpreting interactions. Thousand Oaks, CA: Sage Publications.

Amir, N., Klumpp, H., Elias, J., Bedwell, J. S., Yanasak, N., \& Miller, L. S. (2005). Increased Activation of the Anterior Cingulate Cortex During Processing of Disgust Faces in Individuals with Social Phobia. Biological Psychiatry, 57, 975-981.

Amir, N., Najmi, S., Bomyea, J., \& Burns, M. (2010). Disgust and anger in social anxiety. International Journal of Cognitive Therapy, 3, 3-10.

Ausubel, D. P. (1955). Relationships between shame and guilt in the socialization process. Psychological Review, 67, 378-390.

Baumeister, R. F., \& Leary, M. R. (1995). The need to belong: Desire for interpersonal attachments as a fundamental human motivation. Psychological Bulletin, 117, 497-529.

Beck, A. T., Steer, R. A., \& Brown, G. K. (1996). Manual for the Beck Depression Inventory (2nd ed.). San Antonio, TX: The Psychological Corporation.

Berle, D., Starcevic, V., Brakoulias, V., Sammut, P., Milicevic, D., Hannan, A., \& Moses, K. (2012). Disgust propensity in obsessive-compulsive disorder: Cross-sectional and prospective relationships. Journal of Behavior Therapy and Experimental Psychiatry, 43, 656-663.

Blascovich, J., Mendes, W. B., Hunter, S. B., Lickel, B., \& Kowai-Bell, N. (2001). Perceiver threat in social interactions with stigmatized others. Journal of Personality and Social Psychology, 80, 253-267.

Brown, M. Z., Linehan, M. M., Comtois, K. A., Murray, A., \& Chapman, A. L. (2009). Shame as a prospective predictor of self-inflicted injury in borderline personality disorder: A multimodal analysis. Behaviour Research and Therapy,47, 815-822.

Burns, G., Keortge, S., Formea, G., \& Sternberger, L. (1996). Revision of the padua inventory of obsessive compulsive disorder symptoms: Distinctions between worry, obsessions, and compulsions. Behavior, Research and Therapy, 34, 163-173.

Buss, D. M., Haselton, M. G., Shackelford, T. K., Bleske, A. L., \& Wakefield, J. C. (1998). Adaptations, exaptations, and spandrels. American Psychologist, 53, 533-548.

Chiao, J.Y. \& Blizinsky, K.D. (2010). Culture-gene coevolution of individualism-collectivism and the serotonin transporter gene (5-HTTLPR). Proceedings of the Royal Society B: Biological Sciences, 277, 529-537. 
Claesson, K., \& Sohlberg, S. (2002). Internalized shame and early interactions characterized by indifference, abandonment and rejection: Replicated findings. Clinical Psychology \& Psychotherapy, 9, 277-284.

Cohen, J. (1992). A power primer. Psychological Bulletin, 112, 155-159.

Cohen, T. R., Wolf, S. T., Panter, A. T., \& Insko, C. A. (2011). Introducing the GASP scale: A new measure of guilt and shame proneness. Journal of Personality and Social Psychology, 100, 947-966.

Coleridge, S. T. (1798/1992). The rime of the ancient mariner and other poems. Mineola, NY: Dover Publications.

Crocker, J., Major, B., \& Steele, C. (1998). Social stigma. In D. T. Gilbert, S. T. Fiske, \& G. Lindzey (Eds.), The handbook of social psychology, Vols. 1 and 2 (4th ed.) (pp. 504-553). New York: McGraw-Hill.

Curtis, V., \& Biran, A. (2001). Dirt, disgust, and disease: Is hygiene in our genes? Perspectives in Biology and Medicine, 44, 17-31.

Curtis, V., Aunger, R., \& Rabie, T. (2004). Evidence that disgust evolved to protect from risk of disease. Proceedings Of The Royal Society B: Biological Sciences, 271, 131-133.

Darwin, C. (1872). The expression of emotion in man and animals. London, England: John Murray.

Dawkins, R. (1976/1989). The selfish gene. New York, NY: Oxford University Press.

de Hooge, I. E., Breugelmans, S. M., \& Zeelenberg, M. (2008). Not so ugly after all: When shame acts as a commitment device. Journal of Personality and Social Psychology, 95, 933-943.

de Hooge, I. E., Zeelenberg, M., \& Breugelmans, S. M. (2010). Restore and protect motivations following shame.Cognition and Emotion, 24, 111-127.

Diamond, J. (1997). Guns, germs, and steel: The fates of human societies. New York, NY: W. W. Norton \& Company.

Dijksterhuis, A., Preston, J., Wegner, D., \& Aarts, H. (2008). Effects of subliminal priming of self and God on self-attribution of authorship for events. Journal of Experimental Social Psychology, 44, 2-9.

Dobyns, H. F. (1983). Their number become thinned: Native American population dynamics in eastern North America. Knoxville, TN: University of Tennessee Press. 
Eisenberger, N. I. (2012). Broken hearts and broken bones: A neural perspective on the similarities between social and physical pain. Current Directions in Psychological Science, 21, 42-47.

Ekman, P. (1970). Universal facial expressions of emotion. California Mental Health Research Digest, 8, 151-158.

Ekman, P., Friesen, W. V., O'Sullivan, M., Chan, A., Diacoyanni-Tarlatzis, I., Heider, K., Krause, R., Lecompte, W. A., Ricci-Bitti, P. E., Scherer, K., Tomita, M., \& Tzavaras, A. (1987). Universals and cultural differences in the judgments of facial expressions of emotion. Journal of Personality and Social Psychology, 53, 712-717.

Faulkner, J., Schaller, M., Park, J., \& Duncan, L. (2004). Evolved disease-avoidance mechanisms and contemporary xenophobic attitudes. Group Processes \& Intergroup Relations, 7, 333-353.

Fedewa, B. A., Burns, L. R., \& Gomez, A. A. (2005). Positive and negative perfectionism and the shame/guilt distinction: Adaptive and maladaptive characteristics. Personality and Individual Differences, 38, 1609-1619.

Ferguson, T. J., Stegge, H., \& Damhuis, I. (1991). Children's understanding of guilt and shame.Child Development,62, 827-839.

Fessler, D. M. T. (2004). Shame in two cultures: Implications for evolutionary approaches. Journal of Cognition and Culture, 4, 207-262.

Fincher, C. L., Thornhill, R., Murray, D. R., \& Schaller, M. (2008). Pathogen prevalence Predicts Human Cross-cultural Variability in Individualism/Collectivism. Proceedings of the Royal Society of London B, 275, 1279-1285.

Friedman, H. S., Riggio, R. E., \& Casella, D. F. (1988). Nonverbal skill, personal charisma, and initial attraction.Personality and Social Psychology Bulletin, 14, 203-211.

Gausel, N., Leach, C. W., Vignoles, V. L., \& Brown, R. (2012). Defend or Repair? Explaining Responses to In-Group Moral Failure by Disentangling Feelings of Shame, Rejection, and Inferiority. Journal of Personality and Social Psychology. Advance online publication.

Gilbert, P. (1997). The evolution of social attractiveness and its role in shame, humiliation, guilt and therapy. British Journal of Medical Psychology, 70, 113-147.

Gilbert, P., McEwan, K., Irons, C., Bhundia, R., Christie, R., Broomhead, C., \& Rockliff, H. (2010). Self-harm in a mixed clinical population: The roles of self-criticism, shame, and social rank. British Journal Of Clinical Psychology,49, 563-576. 
Gilovich, T., Savitsky, K., \& Medvec, V. H. (1998). The illusion of transparency: Biased assessments of others' ability to read one's emotional states. Journal of Personality and Social Psychology, 75, 332-346

Giner-Sorolla, R., \& Espinosa, P. (2011). Social cuing of guilt by anger and of shame by disgust. Psychological Science, 22, 49-53.

Goss, K., \& Allan, S. (2009). Shame, pride and eating disorders. Clinical Psychology \& Psychotherapy, 16, 303-316.

Grasmick, H., Bursik, R., \& Kinsey, K. (1991). Shame and embarrassment as deterrents to noncompliance with the law: The case of an antilittering campaign. Environment and Behavior, 23, 233-251.

Haidt, J., McCauley, C., \& Rozin, P. (1994). Individual differences in sensitivity to disgust: A scale sampling seven domains of disgust elicitors. Personality and Individual Differences, 16, 701-713.

Haidt, J. (2003). The moral emotions. In R. J. Davidson, K. R. Scherer, \& H. H. Goldsmith (Eds.), Handbook of affective sciences (pp. 852-870). Oxford: Oxford University Press.

Hastings, M. E., Northman, L. M., \& Tangney, J. P. (2000). Shame, guilt, and suicide. In T. E. Joiner \& M. D. Rudd (Eds.), Suicide science: Expanding the boundaries (pp. 67-79). New York: Kluwer Academic/Plenum.

Hawthorne, N. (1850/1956). The scarlet letter. New York, NY: Rinehart \& Co., Inc.

Heatherton, T. F., \& Wyland, C. L. (2003). Assessing self-esteem. In S. J. Lopez, C. R. Snyder (Eds.), Positive psychological assessment: A handbook of models and measures (pp. 219-233). Washington, DC US: American Psychological Association.

Horberg, E. J., Oveis, C., Keltner, D., \& Cohen, A. B. (2009). Disgust and the moralization of purity. Journal of Personality and Social Psychology, 97, 963-976.

Hutcherson, C. A., \& Gross, J. J. (2011). The moral emotions: A social-functionalist account of anger, disgust, and contempt. Journal of Personality and Social Psychology, 100, 719737.

Inbar, Y., Pizarro, D.A., Knobe, J., \& Bloom, P. (2009). Disgust sensitivity predicts intuitive disapproval of gays. Emotion, 9, 435-439.

Keltner, D., \& Buswell, B. N. (1996). Evidence for the distinctness of embarrassment, shame, and guilt: A study of recalled antecedents and facial expressions of emotion.Cognition and Emotion, 10, 155-171. 
Kim, S., Thibodeau, R., \& Jorgensen, R. S. (2011). Shame, guilt, and depressive symptoms: A meta-analytic review. Psychological Bulletin, 137, 68-96.

Lewis, H. B. (1971). Shame and guilt in neurosis. New York: International Universities Press.

Marcus, G. (2008). Kluge: The haphazard construction of the human mind. Boston, MA: Houghton Mifflin Co.

Mason, E. C., \& Richardson, R. (2012). Treating disgust in anxiety disorders. Clinical Psychology: Science and Practice, 19, 180-194.

Miller, S. L., \& Maner, J. K. (2011). Sick body, vigilant mind: The biological immune system activates the behavioral immune system. Psychological Science, 22, 1467-1471.

Miller, W. I. (1997). The anatomy of disgust. Cambridge, MA: Harvard University Press.

Mokros, H. B. (1995). Suicide and shame. American Behavioral Scientist, 38, 1091-1103.

Morrison, D., \& Gilbert, P. (2001). Social rank, shame and anger in primary and secondary psychopaths. Journal of Forensic Psychiatry, 12, 330-356.

Murray, D. R., Trudeau, R., \& Schaller, M. (2011). On the origins of cultural differences in conformity: Four tests of the pathogen prevalence hypothesis. Personality and Social Psychology Bulletin, 37, 318-329.

Navarrete, C. D., \& Fessler, D. M. T. (2006). Disease avoidance and ethnocentrism: the effects of disease vulnerability and disgust sensitivity on intergroup attitudes. Evolution and Human Behavior, 27, 270-282.

Nesse, R. M., \& Williams, G. C. (1994). Why we get sick: The new science of Darwinian medicine. New York, NY: Times Books.

Nesse, R. M., \& Ellsworth, P. C. (2009). Evolution, emotions, and emotional disorders. American Psychologist, 64, 129-139.

Nettle, D. (2006). The evolution of personality variation in humans and other animals. American Psychologist, 61, 622-631.

Niedenthal, P. M., Tangney, J. P., \& Gavanski, I. (1994). "If only I weren't" versus "if only I hadn't": Distinguishing shame and guilt in counterfactual thinking. Journal of Personality and Social Psychology, 67, 585-595.

Nussbaum, M.C. (2004). Hiding from humanity. Princeton, NJ: Princeton University Press.

Oakes, M. A., Brown, J. D., \& Cai, H. (2008). Implicit and explicit self-esteem: Measure for measure. Social Cognition, 26, 778-790. 
Oaten, M., Stevenson, R., \& Case, T. (2009). Disgust as a disease-avoidance mechanism. Psychological Bulletin, 135, 303-321.

Olatunji, B. (2008). Disgust, scrupulosity and conservative attitudes about sex: Evidence for a mediational model of homophobia. Journal of Research in Personality, 42, 1364-1369.

Olatunji, B. O., Haidt, J., McKay, D., \& David, B. (2008). Core, animal reminder, and contamination disgust: Three kinds of disgust with distinct personality, behavioral, physiological, and clinical correlates. Journal of Research in Personality, 42, 1243-1259.

Olatunji, B. O., \& McKay, D. (2009). Disgust and its disorders: Theory, assessment, and treatment implications. Washington, DC US: American Psychological Association.

Olatunji, B. O., Williams, N. L., Tolin, D. F., Sawchuck, C. N., Abramowitz, J. S.,Lohr, J. M., \& Elwood, L. S. (2007). The Disgust Scale: Item analysis, factor structure, and suggestions for refinement. Psychological Assessment, 19, 281-297.

Oum, R. E., Lieberman, D., \& Aylward, A. (2011). A feel for disgust: Tactile cues to pathogen presence. Cognition and Emotion, 25, 717-725.

Overton, P. G., Markland, F. E., Taggart, H. S., Bagshaw, G. L., \& Simpson, J. (2008). Selfdisgust mediates the relationship between dysfunctional cognitions and depressive symptomatology. Emotion, 8, 379-385.

Park, J. H., Faulkner, J., \& Schaller, M. (2003). Evolved disease-avoidance processes and contemporary anti-social behavior: Prejudicial attitudes and avoidance of people with physical disabilities. Journal of Nonverbal Behavior, 27, 65-87.

Park, J. H., Schaller, M., \& Crandall, C. S. (2006). Psychological disease-avoidance mechanisms and stigmatization of fat people. Unpublished manuscript, University of Groningen, The Netherlands.

Parker, R. (2003). Body hatred. British Journal of Psychotherapy, 19, 447-464.

Patzer, G. L. (1983). Source credibility as a function of communicator physical attractiveness.Journal of Business Research, 11, 229-241.

Radloff, L. S. (1977). The CES-D Scale: A self-report depression scale for research in the general population. Applied Psychological Measurement, 1, 385-401.

Ricouer, P. (1967). The symbolism of evil. Boston, MA: Beacon Press.

Roseman, I.J. (1984). Cognitive determinants of emotions: A structural theory. In P. Shaver (Ed.), Review of personality and social psychology (pp. 11-36). Beverly Hills, CA: Sage. 
Rydell, R. J., McConnell, A. R., Mackie, D. M., \& Strain, L. M. (2006). Of two minds: Forming and changing valence-inconsistent implicit and explicit attitudes. Psychological Science, $17,954-958$.

Schaller, M. (2006). Parasites, behavioral defenses, and the social psychological mechanisms through which cultures are evoked. Psychological Inquiry, 17, 96-101.

Schaller, M., \& Duncan, L. A. (2007). The behavioral immune system: Its evlolutin and social psychological implications. In Forgas, Haselton, \& von Hippel (Eds.), Evolution and the social mind: Evolutionary psychology and social cognitions (pp. 293-307). New York: Psychology Press.

Schaller, M., Miller, G. E., Gervais, W. M., Yager, S., \& Chen, E. (2010). Mere visual perception of other people's disease symptoms facilitates a more aggressive immune response. Psychological Science, 21, 649-652.

Schmader, T., \& Lickel, B. (2006). The approach and avoidance function of guilt and shame emotions: comparing reactions to self-caused and other-caused wrongdoing. Motivation and Emotion, 30, 43-56.

Schnall, S., Benton, J., \& Harvey, S. (2008). With a clean conscience: Cleanliness reduces the severity of moral judgments. Psychological Science, 19, 1219-1222.

Schnall, S., Haidt, J., Clore, G., \& Jordan, A. (2008). Disgust as embodied moral judgment. Personality and Social Psychology Bulletin, 34, 1096-1109.

Shakespeare, W. (1623/1926). The complete works of William Shakespeare. New York: World Syndicate Company, Inc.

Smith, R. H., Webster, J. M., Parrott, W. G., \& Eyre, H. L. (2002). The role of public exposure in moral and nonmoral shame and guilt. Journal of Personality and Social Psychology, 83, 138-159.

Spruyt, A., Gast, A., \& Moors, A. (2011). The sequential priming paradigm: A primer. In K. Klauer, A. Voss, C. Stahl (Eds.), Cognitive methods in social psychology (pp. 48-77). New York, NY US: Guilford Press.

Tangney, J. P. (1991). Moral affect: The good, the bad, and the ugly. Journal of Personality and Social Psychology, 61, 598-607.

Tangney, J. P., \& Dearing, R. (2002). Shame and guilt. New York, NY: Guilford.

Tangney, J. P. (2003). Self-relevant emotions. In M. R. Leary and J. P. Tangney (Eds.) The handbook of self and identity (pp. 384-400). New York, NY: Guilford Press. 
Tangney, J. P., Stuewig, J., Mashek, D., Kendall, S., Goodman, K. and Taylor, C. (2003, August). Moral Emotions and Psychopathy: Inmates' Shame, Guilt, and Empathy. Paper presented at the American Psychological Association, Toronto, Canada.

Tangney, J. P., \& Stuewig, J. (2004). A moral-emotional perspective on evil persons and evil deeds. In A. G. Miller (Ed.), The social psychology of good and evil (pp. 327-355). New York, NY: Guilford Press.

Tangney, J. P., Stuewig, J., \& Mashek, D. J. (2007). Moral Emotions and Moral Behavior. Annual Review of Psychology, 58, 345-372.

Terrizzi, J. A., Jr., Shook, N. J., \& Ventis, W. L. (2010). Disgust: A predictor of social conservatism and prejudicial attitudes toward homosexuals. Personality and Individual Differences, 49, 587-592.

Terrizzi, J. A., Jr., Shook, N. J., \& McDaniel, M. A. (2013). The behavioral immune system and social conservatism: A meta-analysis. Evolution and Human Behavior, 34, 99-108.

Terrizzi, J. A., Jr., Shook, N. J., \& Ventis, W. L. (2012). Religious conservatism: An evolutionarily evoked disease-avoidance strategy. Religion, Brain \& Behavior, 2, 105120.

Tolin, D. F., Lohr, J. M., Sawchuk, C. N., \& Lee, T. C. (1997). Disgust and disgust sensitivity in blood-injection-injury and spider phobia. Behaviour Research and Therapy, 35, 949-953.

Tybur, J. M., Lieberman, D. L., \& Griskevicius, V. (2009). Microbes, mating, and morality: Individual differences in three functional domains of disgust. Journal of Personality and Social Psychology, 97, 103-122.

Ulrich, O., Berking, M., \& Burkardt, S. (2006). Self-conscious emotions and depression: Rumination explains why shame but not guilt is maladaptive. Personality and Social Psychology Bulletin, 32, 1608-1619.

van Overveld, M., de Jong, P. J., \& Peters, M. L. (2010). The Disgust Propensity and Sensitivity Scale - Revised: Its predictive value for avoidance behavior. Personality and Individual Differences, 49, 706-711.

Viar-Paxton, M. A., \& Olatunji, B. O. (2012). Context effects on habituation to disgust-relevant stimuli. Behavior Modification, 36, 705-722.

Wallbott, H. G. (1998). Bodily expression of emotion. European Journal of Social Psychology, $28,879-896$.

Watson, D., Clark, L., \& Tellegen, A. (1988). Development and validation of brief measures of positive and negative affect: The PANAS scales. Journal of Personality and Social Psychology, 54, 1063-1070. 
Widen, S. C., Christy, A. M., Hewett, K., \& Russell, J. A. (2011). Do proposed facial expressions of contempt, shame, embarrassment, and compassion communicate the predicted emotion?. Cognition and Emotion, 25, 898-906.

Williams, K. D. (2001). Ostracism: The power of silence. New York, NY: Guilford Press.

Williams, K. D., \& Jarvis, B. (2006). Cyberball: A program for use in research on interpersonal ostracism and acceptance. Behavior Research Methods, 38, 174-180. 


\section{Footnotes}

${ }^{1}$ These results appear to be an anomaly. In Studies 2, 3, and 4, guilt was either positively correlated with negative affect or not significantly correlated, as has been found in previous research (Cohen et al., 2011).

${ }^{2}$ Because there are significant sex differences in disgust and shame (i.e., females tend to be more sensitive to disgust and shame; Druschel \& Sherman, 1999; Lewis, 1971), analyses were also conducted controlling for sex. Although the correlations were attenuated when sex was controlled, they remained significant and remained in the predicted direction.

${ }^{3}$ Separate analyses were conducted for each of the measures of shame, guilt, and disgust sensitivity. As the results were relatively consistent across measures, only the analyses with the composite variables are presented. Also, all of the effects remained significant even after controlling for sex. Thus, analyses are reported collapsed across sex. 
Table 1

Means, Standard Deviations, and Cronbach's Alphas for all Measures in Study 1.

\begin{tabular}{llll}
\hline & $M$ & $S D$ & $\alpha$ \\
\hline DS & 2.70 & 0.52 & .91 \\
TDDS-Pathogen & 4.10 & 1.14 & .88 \\
TDDS-Sexual & 3.51 & 1.44 & .84 \\
TDDS-Moral & 3.80 & 1.38 & .81 \\
DPSS-R & 2.68 & 0.68 & .88 \\
$\quad$ Propensity Subscale & 2.88 & 0.74 & .85 \\
$\quad$ Sensitivity Subscale & 2.48 & 0.80 & .82 \\
PI-COWC & 1.52 & 1.00 & .92 \\
TOSCA-Shame & 2.99 & 0.68 & .84 \\
TOSCA-Guilt & 3.98 & 0.66 & .89 \\
GASP-Shame & 4.18 & 1.00 & .79 \\
$\quad$ NSE Subscale & 5.16 & 1.31 & .83 \\
$\quad$ Withdraw Subscale & 3.21 & 1.20 & .76 \\
GASP-Guilt & 5.01 & 1.12 & .84 \\
$\quad$ NBE Subscale & 4.72 & 1.37 & .79 \\
$\quad$ Repair Subscale & 5.33 & 1.12 & .73 \\
PANAS-Negative Affect & 1.71 & 0.69 & .89 \\
\hline
\end{tabular}

DS = Disgust Scale, TDDS = Three Domain Disgust Scale, DPSS-R = Disgust Propensity and Sensitivity Scale-Revised, PI-COWC $=$ Checking Obsessions and Washing Compulsions subscale of the Padua Inventory, TOSCA = Test of Self-Conscious Affect, GASP = Guilt and Shame Proneness, NSE = Negative-Self-Evaluation, NBE = Negative-Behavior-Evaluation, PANAS $=$ Positive and Negative Affect Schedule 
Table 2.

Zero-Order Correlations for all Measures in Study 1

\begin{tabular}{|c|c|c|c|c|c|c|c|c|c|c|c|c|c|c|c|c|c|}
\hline \multirow[b]{2}{*}{ Measure } & \multicolumn{17}{|c|}{$r$} \\
\hline & 1 & 2 & 3 & 4 & 5 & 6 & 7 & 8 & 9 & 10 & 11 & 12 & 13 & 14 & 15 & 16 & 17 \\
\hline 1. DS & & $.65 * *$ & $.62 * *$ & $.15^{*}$ & $.44 * *$ & $.36 * *$ & $.43 * *$ & $.62 * *$ & $.29 * *$ & $.35 *$ & .14 & $.41 * *$ & $.16^{*}$ & $.27 * *$ & $.36 * *$ & .10 & .02 \\
\hline 2. TDDS-Pathogen & & & $.49 * *$ & $.17 *$ & $.42 * *$ & $.34 * *$ & $.39 * *$ & $.49 * *$ & $.25 * *$ & $.27 * *$ & $.17^{*}$ & $.24 * *$ & .11 & $.18^{*}$ & $.19 * *$ & .12 & .01 \\
\hline 3. TDDS-Sexual & & & & $.43 * *$ & $.29 * *$ & .13 & $.39 * *$ & $.48 * *$ & $.31 * *$ & $.33 * *$ & $.21 * *$ & $.32 * *$ & $.23 * *$ & $.29 * *$ & $.38 * *$ & .13 & .04 \\
\hline 4. TDDS-Moral & & & & & $.18^{*}$ & .10 & $.23 * *$ & $.21 * *$ & $.27 * *$ & $.32 * *$ & $.37 * *$ & .13 & $.36 * *$ & $.41 * *$ & $.43^{* *}$ & $.30 * *$ & .03 \\
\hline 5. DPSS-R & & & & & & $.88 * *$ & $.89 * *$ & $.51 * *$ & $.45 * *$ & $.33 * *$ & .14 & $.37 * *$ & .03 & .09 & .13 & .01 & $.22 * *$ \\
\hline 6. DPSS-Propensity & & & & & & & $.57 * *$ & $.32 * *$ & $.31 * *$ & $.26 * *$ & .11 & $.29 * *$ & -.01 & .03 & .07 & -.03 & $.17^{*}$ \\
\hline 7. DPSS-Sensitivity & & & & & & & & $.56 * *$ & $.49 * *$ & $.32 * *$ & .14 & $.37 * *$ & .06 & .13 & $.16^{*}$ & .04 & $.21 * *$ \\
\hline 8. PI-COWC & & & & & & & & & $.27 * *$ & $.24 * *$ & .08 & $.29 * *$ & .04 & $.15^{*}$ & $.24 * *$ & .01 & .04 \\
\hline 9. TOSCA-Shame & & & & & & & & & & $.53 * *$ & $.41 * *$ & $.43 * *$ & $.33 * *$ & $.27 * *$ & $.32 * *$ & $.16^{*}$ & .06 \\
\hline 10. GASP-Shame & & & & & & & & & & & $.81 * *$ & $.77 * *$ & $.38 * *$ & $.57 * *$ & $.61 * *$ & $.41 * *$ & .01 \\
\hline 11. NSE & & & & & & & & & & & & $.25 * *$ & $.52 * *$ & $.68 * *$ & $.63^{* *}$ & $.59 * *$ & -.11 \\
\hline 12. Withdraw & & & & & & & & & & & & & .07 & $.20 * *$ & $.31 * *$ & .02 & .14 \\
\hline 13. TOSCA-Guilt & & & & & & & & & & & & & & $.63 * *$ & $.56^{* *}$ & $.58 * *$ & $-.17 *$ \\
\hline 14. GASP-Guilt & & & & & & & & & & & & & & & $.92 * *$ & $.88 * *$ & $-.16^{*}$ \\
\hline 15. NBE & & & & & & & & & & & & & & & & $.61 * *$ & $-.15^{*}$ \\
\hline 16. Repair & & & & & & & & & & & & & & & & & $-.14 *$ \\
\hline 17. Negative Affect & & & & & & & & & & & & & & & & & \\
\hline
\end{tabular}

Affect, GASP = Guilt and Shame Proneness, NSE = Negative-Self-Evaluation, NBE = Negative-Behavior-Evaluation 
Table 3.

Partial Correlations of Shame and Guilt with Disgust for Study 1

\begin{tabular}{|c|c|c|c|c|c|c|c|c|c|c|}
\hline & \multicolumn{5}{|c|}{ Shame $^{1}$} & \multicolumn{5}{|c|}{ Guilt $^{2}$} \\
\hline & TOSCA & GASPS & NSE & Withdraw & Composite & TOSCA & GASPS & NBE & Repair & Composite \\
\hline $\mathrm{DS}$ & $.27 * *$ & $.27 * *$ & -.01 & $.40 * *$ & $.31 * *$ & .02 & .09 & $.20 *$ & -.06 & .06 \\
\hline TDDS-Pathogen & $.25 * *$ & $.24 * *$ & .12 & $.25 * *$ & $.28 * *$ & -.01 & .00 & -.01 & .00 & -.01 \\
\hline TDDS-Sexual & $.28 * *$ & $.24 * *$ & .03 & $.31 * *$ & $.30 * *$ & .12 & .14 & $.23 * *$ & .01 & .15 \\
\hline TDDS-Moral & .12 & .10 & .11 & .05 & .13 & $.30 * *$ & $.32 * *$ & $.34 * *$ & $.22 * *$ & $.35^{* *}$ \\
\hline DPSS-R & $.47 * *$ & $.34 * *$ & .13 & $.37 * *$ & $.47 * *$ & -.12 & -.16 & -.12 & -.15 & -.16 \\
\hline Propensity & $.33 * *$ & $.26 * *$ & .12 & $.26 * *$ & $.35 * *$ & -.08 & -.11 & -.08 & -.11 & -.11 \\
\hline Sensitivity & $.51 * *$ & $.35 * *$ & .11 & $.40 * *$ & $.50 * *$ & -.13 & $-.17 *$ & -.14 & $-.16 *$ & $-.17 *$ \\
\hline PI-COWC & $.29 * *$ & $.28 * *$ & .07 & $.34 * *$ & $.33 * *$ & -.14 & -.06 & .05 & $-.17 *$ & -.11 \\
\hline
\end{tabular}

${ }^{*} \mathrm{p}<.05,{ }^{*} \mathrm{p}<.01, \mathrm{DS}=$ Disgust Scale, TDDS = Three Domain Disgust Scale, DPSS-R = Disgust Propensity and Sensitivity ScaleRevised, PI-COWC $=$ Checking Obsessions and Washing Compulsions subscale of the Padua Inventory

${ }^{1}$ Controlling for guilt and negative affect

${ }^{2}$ Controlling for shame and negative affect 
Table 4

Means, Standard Deviations, and Cronbach's Alphas for all Measures in Study 2.

\begin{tabular}{llll}
\hline & $M$ & $S D$ & $\alpha$ \\
\hline DS & 2.69 & 0.50 & .89 \\
TDDS-Pathogen & 4.12 & 1.14 & .84 \\
TDDS-Sexual & 3.46 & 1.45 & .84 \\
TDDS-Moral & 3.80 & 1.32 & .87 \\
PVD & & & \\
$\quad 3.90$ & 1.21 & .71 \\
$\quad$ Germ Aversion & 3.23 & 1.37 & .84 \\
$\quad$ Perceived Infectability & 2.90 & 0.64 & .80 \\
TOSCA-Shame & 4.00 & 0.51 & .77 \\
TOSCA-Guilt & 4.09 & 0.92 & .72 \\
GASP-Shame & 5.21 & 1.21 & .69 \\
$\quad$ NSE Subscale & 2.97 & 1.03 & .61 \\
$\quad$ Withdraw Subscale & 5.18 & 0.98 & .79 \\
GASP-Guilt & 4.77 & 1.30 & .74 \\
$\quad$ NBE Subscale & 5.59 & 0.88 & .56 \\
$\quad$ Repair Subscale & 1.46 & 0.55 & .84 \\
PANAS-Negative Affect &
\end{tabular}

DS = Disgust Scale, TDDS $=$ Three Domain Disgust Scale, PVD $=$ Perceived Vulnerability to Disease, TOSCA $=$ Test of Self-Conscious Affect, GASP $=$ Guilt and Shame Proneness, NSE $=$ Negative-Self-Evaluation, NBE = Negative-Behavior-Evaluation, PANAS = Positive and Negative Affect Schedule 
Table 5

Standardized Regression Coefficient and $R^{2}$ Change for the Shame Analysis in Study 2

\begin{tabular}{lll}
\hline & $\beta$ & $R^{2}$ Change \\
\hline Disgust Sensitivity & $.33^{* *}$ & .09 \\
Disgust Manipulation & & \\
$\quad$ Disgust vs. Neutral & -.01 & \\
$\quad$ Disgust vs. Negative & .01 & \\
Interaction & & .05 \\
$\quad$ Disgust vs. Neutral & $-.27^{* *}$ & \\
$\quad$ Disgust vs. Negative & $-.23^{*}$ & \\
\hline
\end{tabular}

$* p<.05, * * p<.01$ 
Table 6

Standardized Regression Coefficient and $R^{2}$ Change for the Shame Analysis in Study 2

\begin{tabular}{lll}
\hline & $\beta$ & $R^{2}$ Change \\
\hline Disgust Sensitivity & $.33^{* *}$ & .09 \\
Disgust Manipulation & & \\
$\quad$ Disgust vs. Neutral & -.01 & \\
$\quad$ Disgust vs. Negative & .06 & \\
Interaction & & .03 \\
$\quad$ Disgust vs. Neutral & $-.21^{*}$ & \\
$\quad$ Disgust vs. Negative & .12 & \\
\hline
\end{tabular}

$* p<.05, * * p<.01$ 
Table 7

Means, Standard Deviations, and Cronbach's Alphas for all Measures in Study 3.

\begin{tabular}{llll}
\hline & $M$ & $S D$ & $\alpha$ \\
\hline DS & 2.62 & 0.53 & .91 \\
TDDS-Pathogen & 4.06 & 1.13 & .79 \\
TDDS-Sexual & 3.12 & 1.49 & .84 \\
TDDS-Moral & 3.83 & 1.20 & .82 \\
DPSS-R & & & \\
$\quad$ Propensity & 3.08 & 0.73 & .79 \\
$\quad$ Sensitivity & 2.49 & 0.84 & .81 \\
PVD & & & \\
$\quad$ Germ Aversion & 4.00 & 1.30 & .77 \\
$\quad$ Perceived Infectability & 3.47 & 1.51 & .90 \\
PI-COWC & 2.45 & 0.85 & .86 \\
TOSCA-Shame & 2.96 & 0.57 & .72 \\
TOSCA-Guilt & 4.08 & 0.51 & .77 \\
GASP-Shame & 4.14 & 0.86 & .72 \\
$\quad$ NSE Subscale & 5.48 & 1.12 & .69 \\
$\quad$ Withdraw Subscale & 2.81 & 0.94 & .59 \\
GASP-Guilt & 5.33 & 0.93 & .75 \\
$\quad$ NBE Subscale & 5.05 & 1.17 & .67 \\
$\quad$ Repair Subscale & 5.60 & 0.94 & .60 \\
PANAS-Negative Affect & 1.41 & 0.50 & .78 \\
\hline DS = Disgust Scale, TDDS = Three Domain Disgust Scale, DPSS-R = Disgust Propensity and \\
Sensitivity Scale-Revised, PVD = Perceived Vulnerability to Disease, PI-COWC = Checking \\
Obsessions and Washing Compulsions subscale of the Padua Inventory, TOSCA = Test of Self- \\
Conscious Affect, GASP = Guilt and Shame Proneness, NSE = Negative-Self-Evaluation, NBE \\
= Negative-Behavior-Evaluation, PANAS = Positive and Negative Affect Schedule
\end{tabular}


Table 8

Standardized Regression Coefficient and $R^{2}$ Change for the Purity Manipulation Analysis in Study 3

\begin{tabular}{lll}
\hline & $\beta$ & $R^{2}$ Change \\
\hline $\begin{array}{l}\text { Disgust Sensitivity } \\
\text { Purity Manipulation }\end{array}$ & $.51^{* *}$ & .26 \\
$\quad$ Purity vs. Neutral & .10 & \\
$\quad$ Purity vs. Positive & .11 & \\
$\begin{array}{l}\text { Interaction } \\
\quad \text { Purity vs. Neutral }\end{array}$ & -.03 & .01 \\
$\quad$ Purity vs. Positive & -.13 & \\
$* * p<.01$ & &
\end{tabular}


Table 9

Standardized Regression Coefficient and $R^{2}$ Change for the Disgust Manipulation Analysis in Study 3

\begin{tabular}{lll}
\hline & $\beta$ & $R^{2}$ Change \\
\hline Disgust Sensitivity & $.47^{* *}$ & .25 \\
Disgust Manipulation & & \\
$\quad$ Disgust vs. Neutral & $.18^{*}$ & \\
$\quad$ Disgust vs. Negative & $.15^{*}$ & \\
Interaction & & .00 \\
$\quad$ Disgust vs. Neutral & .08 & \\
$\quad$ Disgust vs. Negative & .05 & \\
\hline
\end{tabular}

$* p<.05, * * p<.01$ 
Table 10

Means, Standard Deviations, and Cronbach's Alphas for all Measures in Study 4.

\begin{tabular}{llll}
\hline & $M$ & $S D$ & $\alpha$ \\
\hline DS & 2.61 & 0.49 & .88 \\
TDDS-Pathogen & 4.10 & 1.04 & .78 \\
TDDS-Sexual & 3.22 & 1.46 & .84 \\
TDDS-Moral & 3.67 & 1.39 & .89 \\
DPSS-R & & & \\
$\quad$ Propensity & 3.11 & 0.64 & .76 \\
$\quad$ Sensitivity & 2.60 & 0.84 & .82
\end{tabular}

PVD

$\begin{array}{llll}\text { Germ Aversion } & 4.04 & 1.21 & .77\end{array}$

$\begin{array}{llll}\text { Perceived Infectability } & 3.51 & 1.44 & .91\end{array}$

$\begin{array}{llll}\text { PI-COWC } & 2.61 & 0.94 & .89\end{array}$

$\begin{array}{llll}\text { TOSCA-Shame } & 3.07 & 0.54 & .73\end{array}$

$\begin{array}{llll}\text { TOSCA-Guilt } & 4.08 & 0.39 & .65\end{array}$

$\begin{array}{llll}\text { GASP-Shame } & 5.67 & 0.97 & .73\end{array}$

$\begin{array}{llll}\text { NSE Subscale } & 5.21 & 1.21 & .65\end{array}$

$\begin{array}{llll}\text { Withdraw Subscale } & 2.92 & 1.12 & .70\end{array}$

$\begin{array}{llll}\text { GASP-Guilt } & 5.53 & 0.88 & .76\end{array}$

$\begin{array}{llll}\text { NBE Subscale } & 5.25 & 1.09 & .66\end{array}$

$\begin{array}{llll}\text { Repair Subscale } & 5.81 & 0.85 & .60\end{array}$

$\begin{array}{llll}\text { PANAS-Negative Affect } & 1.45 & 0.58 & .85\end{array}$

DS $=$ Disgust Scale, TDDS $=$ Three Domain Disgust Scale, DPSS-R $=$ Disgust Propensity and Sensitivity Scale-Revised, PVD = Perceived Vulnerability to Disease, PI-COWC $=$ Checking Obsessions and Washing Compulsions subscale of the Padua Inventory, TOSCA = Test of SelfConscious Affect, GASP = Guilt and Shame Proneness, NSE = Negative-Self-Evaluation, NBE $=$ Negative-Behavior-Evaluation, PANAS $=$ Positive and Negative Affect Schedule 
Table 11

Standardized Regression Coefficient and $R^{2}$ Change for the Shame Analysis in Study 4

\begin{tabular}{lll}
\hline & $\beta$ & $R^{2}$ Change \\
\hline Disgust Sensitivity & $.49 * *$ & .24 \\
Disgust Manipulation & .03 & \\
Interaction & $-.23 * *$ & .03 \\
\hline
\end{tabular}

$* * p<.01$ 


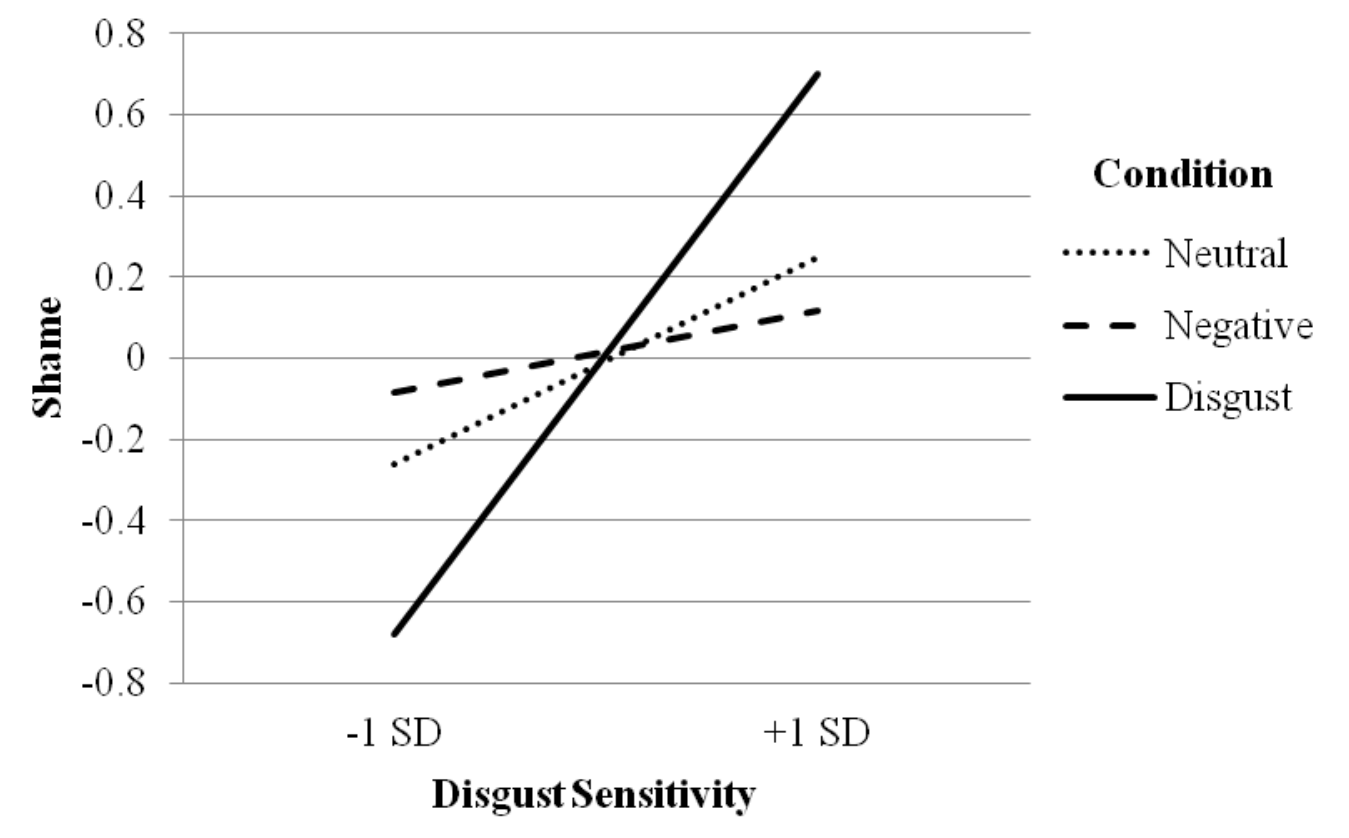

Figure 1. Condition by Disgust Sensitivty Interaction predicting Shame in Study 2 


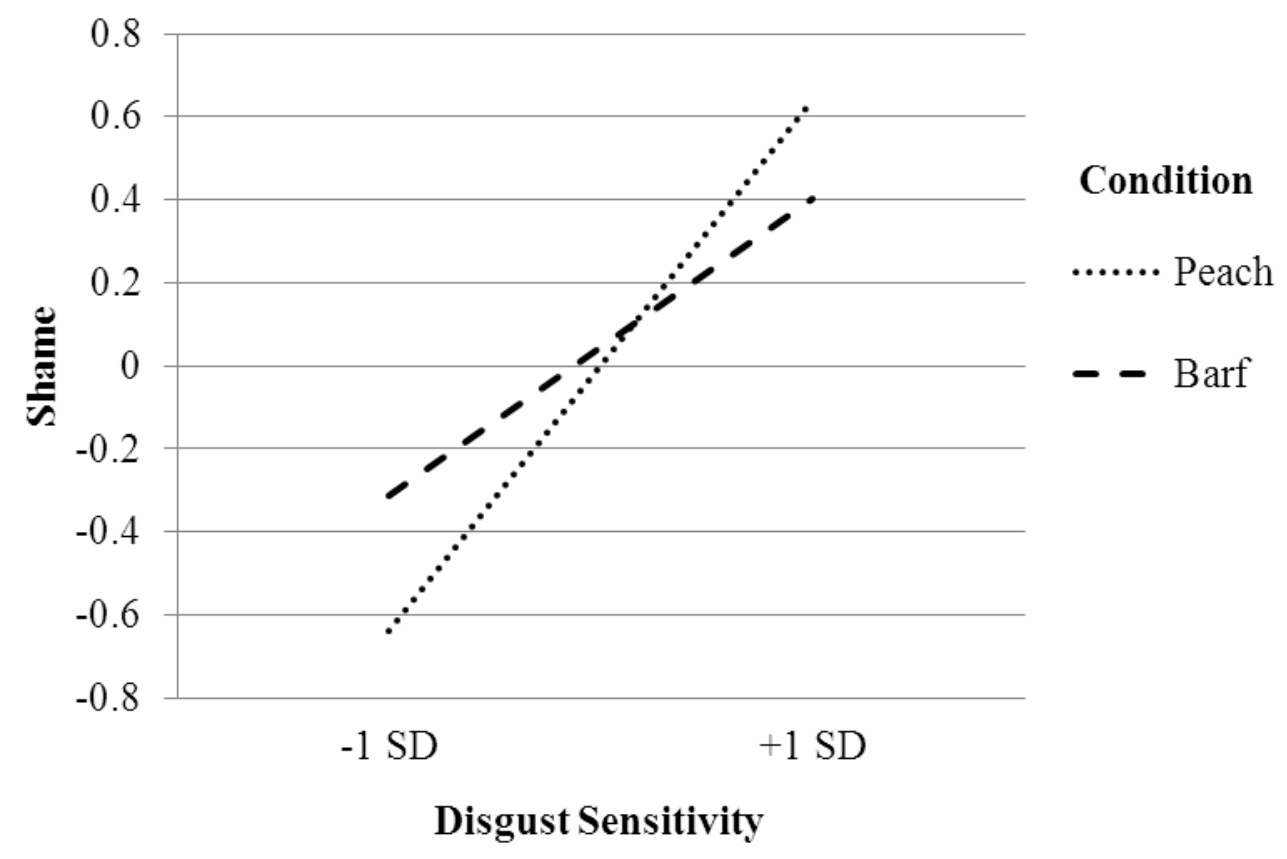

Figure 2. Interaction between Condition and Disgust Sensitivity predicting Shame in Study 4. 


\section{Appendix A: Questionnaires}

Disgust Scale (Haidt et al., 1994)

Three Domain Disgust Scale (Tybur et al., 2009)

Disgust Propensity and Sensitivity Scale-Revised (van Overveld et al., 2006)

Contamination Obsessions and Washing Compulsions Subscale (Burns et al., 1996)

Perceived Vulnerability to Disease Scale (Duncan et al., 2009)

Test of Self-Conscious Affect (Tangney \& Dearing, 2002)

Guilt and Shame Proneness Scale (Cohen et al., in press)

Positive and Negative Affect Schedule (Watson et al., 1988)

Demographics 


\section{Disgust (Haidt, McCauley, \& Rozin, 1994)}

Responses for items 1 through 16 can range from 1 to 4, 1 being strongly disagree and 4 being strongly agree. Responses for items 17-32 can range from 1 to 4, 1 being not disgusting at all and 4 being very disgusting.

1. I might be willing to try eating monkey meat, under some circumstances.

2. I try to avoid letting any part of my body touch the toilet seat in a public restroom, even when it appears clean.

3. It would bother me to be in a science class, and to see a human hand preserved in a jar.

4. It would make me uncomfortable to hear a couple making love in the next room of a hotel.

5. If I see someone vomit, it makes me sick to my stomach.

6. I have no problem buying and wearing shirts from used clothing stores.

7. It would bother me tremendously to touch a dead body.

8. It would bother me to see photos of two people having oral sex.

9. Seeing a cockroach in someone else's house does not bother me.

10. I probably would not go to my favorite restaurant if I found out that the cook had a cold.

11. It would bother me to sleep in a nice hotel room if I knew that a man had died of a heart attack in that room the night before.

12. It is OK with me if people want to look at pornography involving animals.

13. Even if I was hungry, I would not drink a bowl of my favorite soup if it had been stirred by a used but thoroughly washed fly-swatter.

14. I would not hold a dollar bill between my lips (like if I needed a free hand), because so many strangers have touched it with their dirty hands.

15. If I were properly trained, I would be willing to help draw blood in a blood drive.

16. I think that people who masturbate every day are degrading themselves.

17. You see maggots on a piece of meat in an outdoor garbage pail.

18. You take a sip of soda and then realize that you picked up the wrong can, which a stranger had been drinking out of.

19. You see someone accidentally stick a fishing hook through his finger.

20. You hear about a 30 year old man who seeks sexual relationships with 80 year old women.

21. While you are walking through a tunnel under a railroad track, you smell urine.

22. You sit down on a public bus, and feel that the seat is still warm from the last person who sat there.

23. You see a man with his intestines exposed after an accident.

24. As part of a sex education class, you are required to inflate a new unlubricated condom, using your mouth.

25. A friend offers you a piece of chocolate shaped like dog-doo.

26. You find out that someone you despise used to live in your house, and sleep in your bedroom.

27. Your friend's pet cat dies, and you have to pick up the dead body with your bare hands.

28. You hear about an adult brother and sister who like to have sex with each other.

29. You see a bowel movement left unflushed in a public toilet.

30. While traveling for 2 weeks with a friend, you discover that your underwear got mixed up in the wash, and you are wearing your friend's underwear.

31. You accidentally touch the ashes of a person who has been cremated.

32. While walking through a park, you see two dogs mating (having sex) 


\section{Three Domain Disgust Scale (Tybur et al., 2009)}

The following items describe a variety of concepts. Please rate how disgusting you find the concepts described in the items, where 0 means that you do not find the concept disgusting at all, and 6 means that you find the concept extremely disgusting.

1. Shoplifting a candy bar from a convenience store

2. Hearing two strangers having sex

3. Stepping on dog poop

4. Stealing from a neighbor

5. Performing oral sex

6. Sitting next to someone who has red sores on their arm

7. A student cheating to get good grades

8. Watching a pornographic video

9. Shaking hands with a stranger who has sweaty palms

10. Deceiving a friend

11. Finding out that someone you don't like has sexual fantasies about you

12. Seeing some mold on old leftovers in your refrigerator

13. Forging someone's signature on a legal document

14. Bringing someone you just met back to your room to have sex

15. Standing close to a person who has body odor

16. Cutting to the front of a line to purchase the last few tickets to a show

17. A stranger of the opposite sex intentionally rubbing your thigh in an elevator

18. Seeing a cockroach run across the floor

19. Intentionally lying during a business transaction

20. Having anal sex with someone of the opposite sex

21. Accidentally touching a person's bloody cut 
Disgust Propensity and Sensitivity Scale-Revised (van Overveld et al., 2006)

Respond to the following items on a scale from 1 to 5,1 being never and 5 being always.

1. I screw up my face in disgust.

2. Disgusting things make my stomach turn.

3. I experience disgust.

4. I find something disgusting.

5. I feel repulsed.

6. When I experience disgust, it is an intense feeling.

7. I become disgusted more easily than other people.

8. I avoid disgusting things.

9. It scares me when I feel faint.

10. It scares me when I feel nauseous.

11. When I feel disgusted, I worry that I might pass out.

12. I think feeling disgust is bad for me.

13. I think disgusting items could cause me illness/infection

14. I worry that I might swallow a disgusting thing.

15. It embarrasses me when I feel disgusted.

16. When I notice that I feel nauseous, I worry about vomiting. 
Contamination Obsessions and Washing Compulsions Subscale (Burns et al., 1996)

Respond to the following items on a scale of 0 to 4, 0 being Not at All and 4 being Very Much.

1. I feel my hands are dirty when I touch money.

2. I think even slight contact with bodily secretions (sweat, saliva, etc.) may contaminate my clothes or somehow harm me.

3. I find it difficult to touch an object when I know it has been touched by strangers or by certain people.

4. I find it difficult to touch garbage or dirty things.

5. I avoid using public toilets because I am afraid of disease and contamination.

6. I avoid using public telephones because I am afraid of contagion and disease.

7. I wash my hands more often and longer than necessary.

8. I sometimes have to wash or clean myself simply because I think I may be dirty or 'contaminated'.

9. If I touch something I think is 'contaminated', I immediately have to wash or clean myself.

10. If an animal touches me, I feel dirty and immediately have to wash myself or change my clothing. 


\section{Perceived Vulnerability to Disease (Duncan et al., 2009)}

Respond to the following items on a scale of 1 to 7,1 being strongly disagree and 7 being strongly agree.

1. In general, I am very susceptible to colds, flu and other infectious diseases.

2. I am unlikely to catch a cold, flu or other illness, even if it is 'going around'. (reverse-scored)

3. If an illness is 'going around', I will get it.

4. My immune system protects me from most illnesses that other people get. (reverse-scored)

5. I am more likely than the people around me to catch an infectious disease.

6. My past experiences make me believe I am not likely to get sick even when my friends are sick. (reverse-scored)

7. I have a history of susceptibility to infectious disease.

8. I prefer to wash my hands pretty soon after shaking someone's hand.

9. I avoid using public telephones because of the risk that I may catch something from the previous user.

10. I do not like to write with a pencil someone else has obviously chewed on.

11. I dislike wearing used clothes because you do not know what the last person who wore it was like.

12. I am comfortable sharing a water bottle with a friend. (reverse-scored)

13. It really bothers me when people sneeze without covering their mouths.

14. It does not make me anxious to be around sick people. (reverse-scored)

15. My hands do not feel dirty after touching money. (reverse-scored) 


\section{Test of Self-Conscious Affect (Tangney \& Dearing, 2002)}

Imagine the following scenarios and respond to the items on a scale from 1 to 5,1 being not likely and 5 being very likely.

1. You make plans to meet a friend for lunch. At 5 o'clock, you realize you stood your friend up.

a. You would think: "I'm inconsiderate."

b. You'd think you should make it up to your friend as soon as possible.

2. You break something at work and then hide it.

a. You would think: "This is making me anxious. I need to either fix it or get someone else to."

b. You would think about quitting.

3. You are out with friends one evening, and you're feeling especially witty and attractive. Your best friend's spouse seems to particularly enjoy your company.

a. You would think: "I should have been aware of what my best friend was feeling."

b. You would probably avoid eye contact for a long time.

4. At work, you wait until the last minute to plan a project, and it turns out badly.

a. You would feel incompetent.

b. You would feel: "I deserve to be reprimanded for mismanaging the project."

5. You make a mistake at work and find out a coworker is blamed for the error.

a. You would keep quiet and avoid the coworker.

b. You would feel unhappy and eager to correct the situation.

6. For several days you put off making a difficult phone call. At the last minute you make the call and are able to manipulate the conversation so that all goes well.

a. You would regret that you put it off.

b. You would feel like a coward.

7. While playing around you throw a ball and it hits your friend in the face.

a. You would feel inadequate that you can't even throw a ball.

b. You would apologize and make sure your friend feels better.

8. You have recently moved away from your family, and everyone has been very helpful. A few times you needed to borrow money, but you paid it back as soon as you could.

a. You feel immature.

b. You would return the favor as quickly as you could.

9. You are driving down the road, and you hit a small animal.

a. You would think: "I'm terrible."

b. You'd feel bad you hadn't been more alert driving down the road.

10. You walk out of an exam thinking you did extremely well. Then you find out you did poorly.

a. You would think: "I should have studied harder."

b. You would feel stupid.

11. You and a group of coworkers worked very hard on a project. Your boss singles you out for a bonus because the project was such a success.

a. You would feel alone and apart from your colleagues.

b. You would feel you should not accept it.

12. While out with a group of friends, you make fun of a friend who's not there. 
a. You would feel small...like a rat.

b. You would apologize and talk about that person's good points.

13. You make a big mistake on an important project at work. People were depending on you, and your boss criticizes you.

a. You would feel like you wanted to hide.

b. You would think: "I should have recognized the problem and done a better job."

14. You volunteer to help with the local Special Olympics for handicapped children. It turns out to be frustrating and time-consuming work. You think seriously about quitting, but then you see how happy the kids are.

a. You would feel selfish, and you'd think you are basically lazy.

b. You would think: "I should be more concerned about people who are less fortunate."

15. You are taking care of your friend's dog while your friend is on vacation, and the dog runs away.

a. You would think, "I am irresponsible."

b. You would vow to be more careful next time.

16. You attend your coworker's housewarming party and you spill red wine on a new creamcolored carpet, but you think no one notices.

a. You would stay late to help clean up the stain after the party.

b. You would wish you were anywhere but at the party.

(shame items 1a, 2b, 3b, 4a, 5a, 6b, 7a, 8a, 9a, 10b, 11a, 12a, 13a, 14a, 15a, 16b) 


\section{Guilt and Shame Proneness Scale (Cohen, et al., in press)}

Guilt and Shame Proneness (GASP) Scale

Instructions: In this questionnaire you will read about situations that people are likely to encounter in day-to-day life, followed by common reactions to those situations. As you read each scenario, try to imagine yourself in that situation. Then indicate the likelihood that you would react in the way described.
1
23
4
5
$6 \quad 7$

Very Unlikely Unlikely Slightly Unlikely About 50\% Likely Slightly Likely Likely Very Likely

1. After realizing you have received too much change at a store, you decide to keep it because the salesclerk doesn't notice. What is the likelihood that you would feel uncomfortable about keeping the money?

2. You are privately informed that you are the only one in your group that did not make the honor society because you skipped too many days of school. What is the likelihood that this would lead you to become more responsible about attending school?

3. You rip an article out of a journal in the library and take it with you. Your teacher discovers what you did and tells the librarian and your entire class. What is the likelihood that this would make you would feel like a bad person?

4. After making a big mistake on an important project at work in which people were depending on you, your boss criticizes you in front of your coworkers. What is the likelihood that you would feign sickness and leave work?

5. You reveal a friend's secret, though your friend never finds out. What is the likelihood that your failure to keep the secret would lead you to exert extra effort to keep secrets in the future? 6. You give a bad presentation at work. Afterwards your boss tells your coworkers it was your fault that your company lost the contract. What is the likelihood that you would feel incompetent?

7. A friend tells you that you boast a great deal. What is the likelihood that you would stop spending time with that friend?

8. Your home is very messy and unexpected guests knock on your door and invite themselves in. What is the likelihood that you would avoid the guests until they leave?

9. You secretly commit a felony. What is the likelihood that you would feel remorse about breaking the law?

10. You successfully exaggerate your damages in a lawsuit. Months later, your lies are discovered and you are charged with perjury. What is the likelihood that you would think you are a despicable human being?

11. You strongly defend a point of view in a discussion, and though nobody was aware of it, you realize that you were wrong. What is the likelihood that this would make you think more carefully before you speak?

12. You take office supplies home for personal use and are caught by your boss. What is the likelihood that this would lead you to quit your job?

13. Because of your carelessness, you break something you borrowed from a friend, though your friend never notices. What is the likelihood that you would replace what you broke? 
14. You make a mistake at work and find out a coworker is blamed for the error. Later, your coworker confronts you about your mistake. What is the likelihood that you would feel like a coward?

15. You make a strong argument in a debate but the moderator points out to everyone that your facts are incorrect. What is the likelihood that you would feel like an idiot?

16. You falsify some information in a job application though it is never discovered. What is the likelihood that you would feel that the way you acted was despicable?

17. While you are out with friends, someone you knowingly deceived tells your friends that you are a liar. What is the likelihood that you would quickly leave and go home?

18. At a coworker's housewarming party, you spill red wine on their new cream-colored carpet. You cover the stain with a chair so that nobody notices your mess. What is the likelihood that you would feel that the way you acted was pathetic?

19. While discussing a heated subject with friends, you suddenly realize you are shouting though nobody seems to notice. What is the likelihood that you would try to act more considerately toward your friends?

20. You lie to people but they never find out about it. What is the likelihood that you would feel terrible about the lies you told?

\section{GASP SCORING}

Guilt-Negative-Behavior-Evaluation (NBE): 1, 9, 16, 18, 20

Guilt-Repair: 2, 5, 11, 13, 19

Shame-Negative-Self-Evaluation (NSE): 3, 6, 10, 14, 15

Shame-Withdraw: 4, 7, 8, 12, 17 


\section{Positive and Negative Affect Schedule (Watson et al., 1988)}

This scale consists of a number of words that describe different feelings and emotions. Read each item and then mark the appropriate answer in the space next to that word. Indicate the extent to which you feel this way right now, at the present moment. Use the following scale to record your answers.

$\begin{array}{lcccr}1 & 2 & 3 & 4 & 5 \\ \text { very slightly } & \text { a little } & \text { moderately } & \text { quite a bit } & \text { extremely }\end{array}$ or not at all

interested

distressed

excited

upset

strong

guilty

scared

hostile

enthusiastic

proud

irritable

alert ashamed

inspired

nervous

determined

attentive

jittery

active afraid 


\section{Demographic Information}

Age:

Ethnicity: (Check all that apply)

African

African-American

Arab/Arab-American

Asian/Asian-American

Caribbean

_Hispanic/Hispanic-American

Native-American

Pacific Islander

White/Caucasian

Other

Gender: (circle one) 1) Male

2) Female

Please indicate your age:

What political party best represents your beliefs?

_ Democrat __ Republican ___ Libertarian __ Independent __ Other

What is your religious affiliation (check one):

Christian - Protestant

Muslim

Christian - Catholic

Jewish

Hindu

Atheist

Buddhist

Agnostic

Not religious

Other - Please list:

How would you characterize your hometown? (check one)

rural (unincorporated)

small town (village or town)

suburban (metropolitan area of a large city)

small city (population $<30,000$ )

medium-sized city (population 30,000 - 100,000)

large city (population $>100,000$ ) 


\section{Appendix B: Primes}

\begin{tabular}{lllll}
\hline Disgust & Negative & Neutral & Positive & Purity \\
\hline Pus & Pity & Plain & Joy & New \\
Fart & Fault & Farm & Calm & Clean \\
Scab & Scar & Square & Smile & Shower \\
Snot & Snob & Street & Laugh & Soap \\
Puke & Pinch & Plant & Happy & Bathe \\
Poop & Penalty & Paper & Friendly & Fresh \\
Urine & Useless & Unit & Pleasant & New \\
Vomit & Vandal & Vest & Bliss & Rinse \\
Mucus & Maniac & Month & Amazed & Cleansed \\
Diarrhea & Disappointing & Door & Cheer & Washed \\
\hline
\end{tabular}




\section{Vita}

John Anthony Terrizzi Jr. was born on July 31, 1981 in Huntingdon, Pennsylvania. He graduated from Huntingdon Area High School in 1999 and earned his Bachelor of Science in Psychology from Juniata College in 2004. In 2007, he earned his Master of Arts in General Experimental Psychology from the College of William and Mary. He began his Doctor of Philosophy in Psychology at Virginia Commonwealth University in 2008. In 2011, he transferred to West Virginia University with his advisor, Natalie Shook, where he finished his $\mathrm{PhD}$ in 2013. His research focuses on the social psychological implications of the behavioral immune system and his work has been published in journals such as Personality and Individual Differences; Social Psychology; Religion, Brain \& Behavior; and Evolution and Human Behavior. 